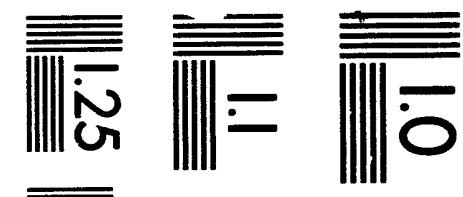

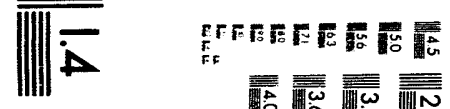

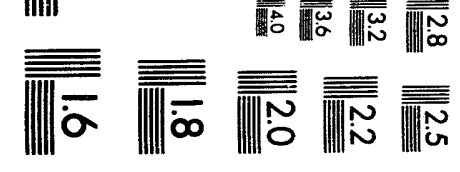



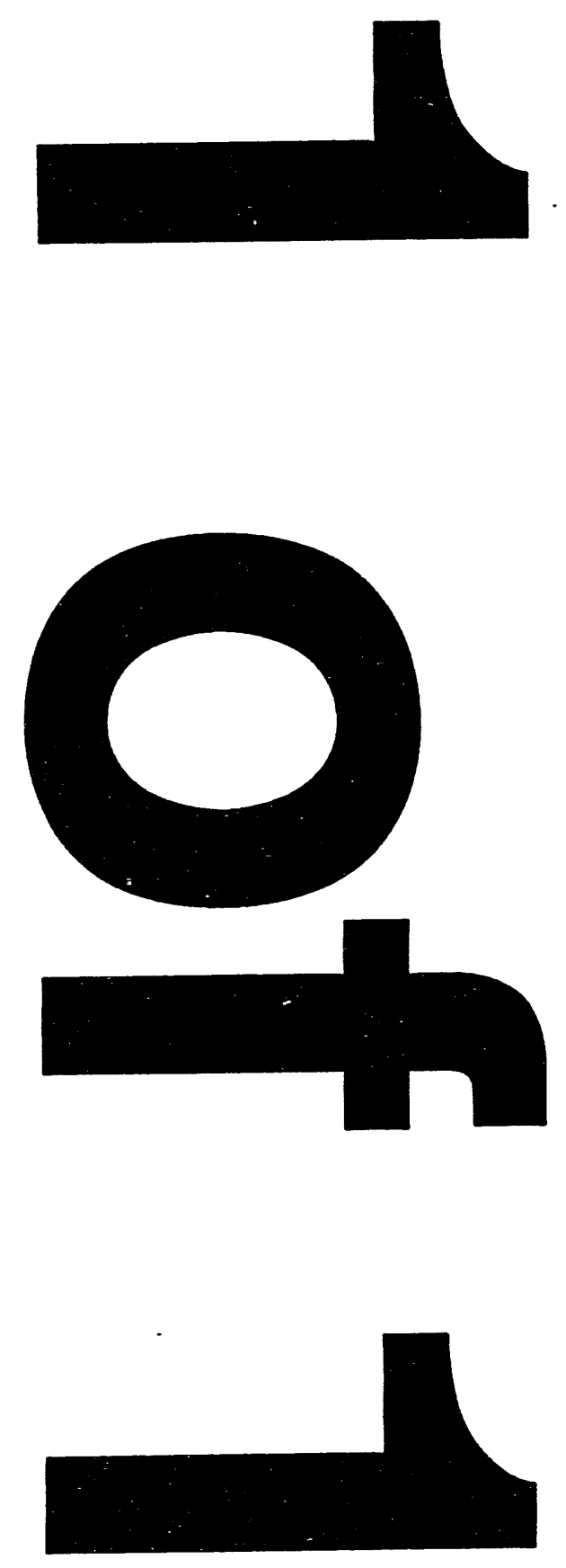
ORNLTM-12483

Dist. Category UC-420

Fusion Energy Division

\section{THE IMPACT OF IMPROVED PHYSICS ON COMMERCIAL TOKAMAK REACTORS}
J. D. Galambos
S. Haney*
L. J. Perkins*
J. Mandrekas ${ }^{\dagger}$

*Lawrence Livermore National Laboratory.

†Georgia Institute of Technology.

Date Published: January 1994

Prepared for the DOE Office of Fusion Energy DOE Budget Activity No. 613086707

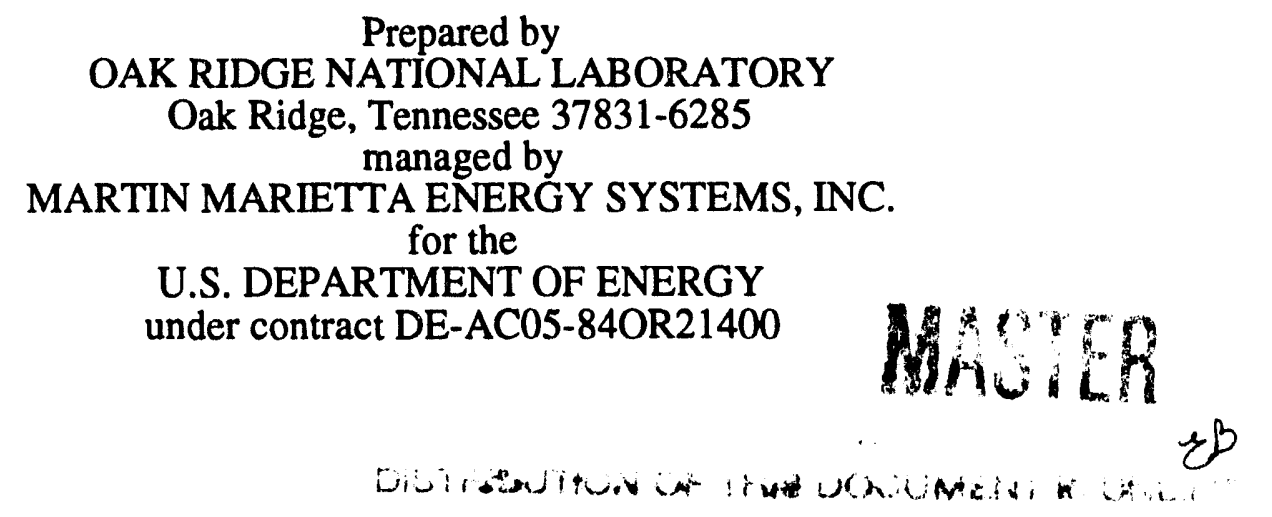




\section{CONTENTS}

Page

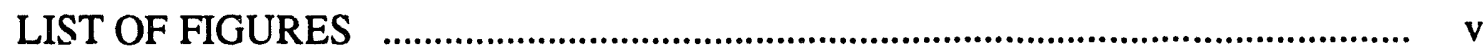

LIST OF TABLES …................................................................................ vii

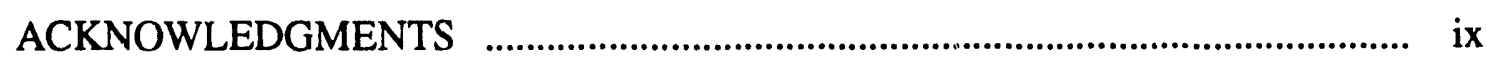

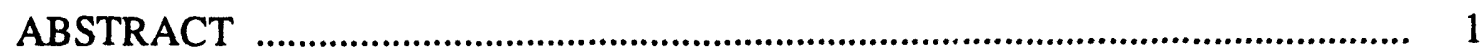

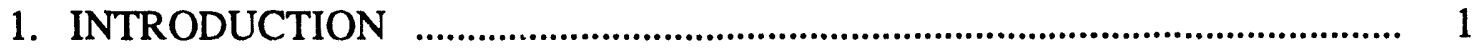

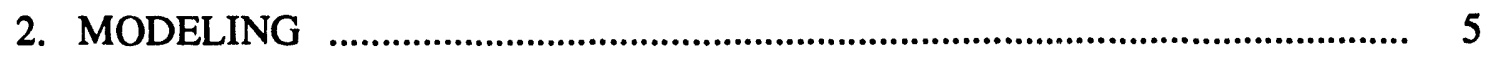

2.1 PHYSICS MODEL ........................................................................... 5

2.1.1 Impurity Ion Concentrations .......................................................... 5

2.1.2 Plasma Power Balance .............................................................. 5

2.1.3 Maximum Beta ............................................................................... 7

2.1.4 MHD Requirements ............................................................... 7

2.1.5 Current Drive ......................................................................... 7

2.1.6 Alpha Confinement .................................................................... 7

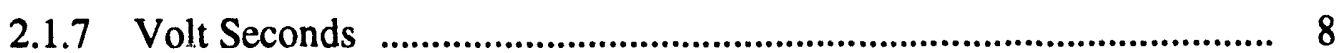

2.1.8 Divertor Heat Load ................................................................... 9

2.2 ENGINEERING CONSTRAINTS …................................................... 9

2.2.1 TF Coils ............................................................................... 9

2.2.2 OH Coils ............................................................................. 10

2.2.3 TF Ripple ......................................................................... 10

2.2.4 Shielding ................................................................................ 11

2.2.5 Inner Divertor Space ..................................................................... 11

2.2.6 Injection Power Limit ............................................................ 11

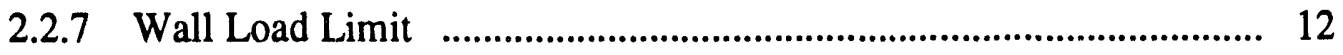

2.3 REACTOR MODELING ............................................................... 12

2.3.1 Reactor Power Balance .......................................................... 13

2.3.2 Cost of Electricity .................................................................. 14

2.3.3 Capital Cost _............................................................................ 14

2.3.4 Fuel Costs ........................................................................... 15

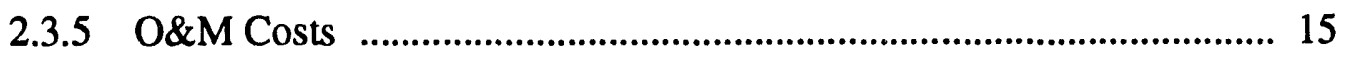

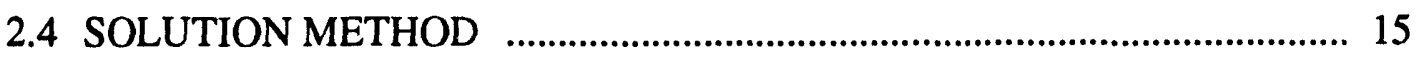




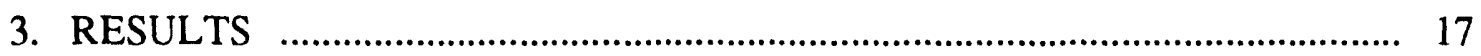

3.1 STEADY-STATE REACTORS ………............................................ 17

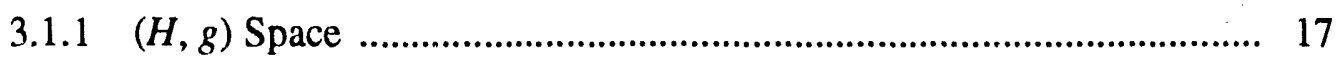

3.1.2 Current Drive Efficiency …….................................................. 20

3.1.3 Economy of Scale ................................................................ 20

3.1.4 High $q_{95}$ Operation ................................................................... 24

3.2 PULSED REACTORS ….............................................................. 25

3.2.1 Pulsed Reactor $(H, g)$ Space …………..................................... 25

3.2.2 Pulsed Reactor Economy of Scale Sensitivity .................................. 27

3.2.3 Pulsed Reactor Burn Time Sensitivity ........................................... 27

3.3 PULSED ITER-LIKE REACTORS ….............................................. 30

3.3.1 Pulsed ITER-Like Reactors $(H, g)$ Space ..................................... 31

3.3.2 Pulsed ITER-Like Reactors, Economy of Scale .............................. 33

3.3.3 Pulsed ITER-Like Reactors, Burn Time Sensitivity ......................... 33

3.4 REACTORS WITH NO $H$ OR $g$ LIMITS ............................................ 34

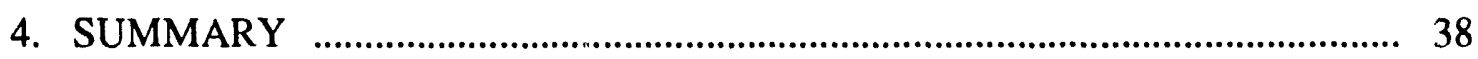

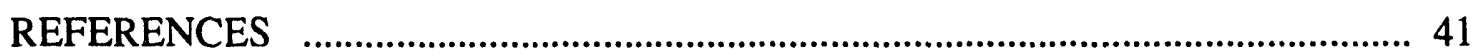

Appendix A. DIRECT COST CALCULATION .................................................. 43 


\section{LIST OF FIGURES}

Figure

1. Minimum COE steady-state reactor parameters in $(H, g)$ space

2. Variation of useful ITER-89 confinement scaling $H$ factor vs maximum allowed $H$ factor, for various Troyon beta limit coefficients $g$, for the nominal steady-state reactor

3. Minimum COE steady-state reactor parameters in $(H, g)$ space with current drive efficiency improved by a factor of 3

4. Minimum COE steady-state reactor parameters vs net electric output

5. Minimum COE steady-state reactor parameters vs net electric output with $q_{95} \geq 5$

6. Minimum $\mathrm{COE}$ pulsed reactor parameters in $(H, g)$ space

7. Variation of useful ITER-89 confinement scaling $H$ factor vs maximum allowed $H$ factor, for various Troyon beta limit coefficients $g$, for pulsed reactor

8. Minimum COE pulsed reactor parameters vs net electric output with 10 -h burn time

9. Minimum COE pulsed reactor parameters vs pulse length for 1000-MW(e) case

10. Minimum COE pulsed reactor parameters in $(H, g)$ space using ITER-EDA-like rules

11. Variation of useful ITER-89 confinement scaling $H$ factor vs maximum allowed $H$ factor, for various Troyon beta limit coefficients $g$, for ITER-like pulsed reactors

12. Minimum COE pulsed reactor parameters vs net electric output with 10 -h burn time using ITER-EDA-like rules

13. Minimum COE pulsed reactor parameters vs pulse length for 1000-MW(e) case using ITER-EDA-like rules

14. Minimum COE steady-state reactor parameters with no $H$ factor or $g$ limits vs net electric output 


\section{LIST OF TABLES}

Table

Page

1 Summary of the plasma and device constraints applied in this study

3

2 Reactor types examined in this study and motivating reasons for examining them

4

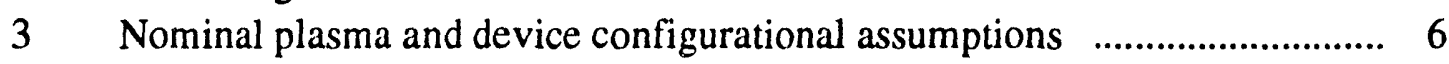

4 Assumptions used in the plant power balance and cost of electricity calculation 12

5 Quantities used as variables in the solution process .................................. 16

6 Minimum COE, steady-state, current-driven reactor parameters .................. 23

7 Minimum COE, inductively pulsed, extrapolated reactor parameters $\ldots . . . . . .29$

8 Minimum COE, pulsed, ITER-like extrapolated reactor parameters ........... 32

9 Neoclassical confinement reactor parameters ......................................... 36

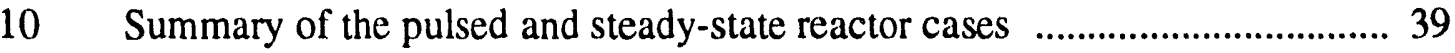

A.1 Direct cost scalings used in the SUPERCODE ............................................ 44 


\section{ACKNOWLEDGMENTS}

The authors take pleasure in thanking William M. Nevins, Keith I. Thomassen, G. Hutch Neilson, J. Freidberg, J. Sheffield, and especially Robert Goldston for their many helpful comments and suggestions during the performance of this study. 


\title{
THE IMPACT OF IMPROVED PHYSICS ON COMMERCIAL TOKAMAK REACTORS
}

\author{
J. D. Galambos \\ L. J. Perkins
}

S. Haney

J. Mandrekas

\begin{abstract}
Improvements in the confinement and beta capability of tokamak devices have long been a goal of the fusion program. We examine the impact of improvements in present day confinement and beta capabilities on commercial tokamak reactors. We characterize confinement with the achievable enhancement factor $(H)$ over the ITER89 Power scaling confinement time, and beta by the Troyon coefficient $g$. A surprisingly narrow range of plasma confinement and beta are found to be useful in minimizing the cost of electricity for a tokamak reactor. Improvements in only one of these quantities is not useful beyond some point, without accompanying improvements in the other. For the plasma beta limited by a Troyon coefficient $(\mathrm{g})$ near 4.3 (\% $\mathrm{mT} / \mathrm{MA}$ ), confinement levels characterized by $H$ factor enhancements of only 2 are useful for our nominal steady-state driven tokamak. These confinement levels are similar to those observed in present day experiments. If the permissible Troyon beta coefficient is near 6, the useful $H$ factor confinement range increases to 2.5 , still close to present day confinement levels. Inductively driven, pulsed reactors have somewhat increased useful ranges of confinement, relative to the steadystate cases. For a Troyon beta limit coefficient $g$ near $4.3, H$ factors up to 2.5 are useful, and for $g$ near $6, H$ factors up to 3 are useful.
\end{abstract}

\section{INTRODUCTION}

A key element in planning the next generation of Tokamak experiments 1,2 is the impact these experiments will have on DEMO and future power reactors. Namely, can next-generation experiments identify regimes of operation that result in power reactors that are built at smaller unit size and cost, have higher power density, and that ultimately are more competitive with other power sources? The mission of the proposed Tokamak Physics Experiment (TPX) ${ }^{1}$ device is to investigate advanced physics operations for tokamaks to benefit future tokamak reactors. However, the question remains: which physics improvements offer the most advantage to the tokamak reactor concept, and what is the magnitude of these benefits? Is it better to push for beta improvements or confinement improvements? These questions are addressed by showing the impact of these physics improvements on commercial tokamak power reactors.

We use the SUPERCODE systems code 3 as the vehicle for this study. This code is particularly useful for this sort of study because of its flexible optimization package. We utilize global plasma physics modeling typical of reactor studies and include a coupled engineering analysis that was developed to model the International Thermonuclear Experimental Reactor Conceptual Design Activity (ITER CDA) device. We have also 
incorporated standard power reactor models into SUPERCODE and are able to examine the impact of physics assumptions on the minimum cost of electricity (COE) of a tokamak power reactor. The modeling is described in Chap. 2, and the primary constraints considered in this report are summarized in Table 1. Previous tokamak reactor studies ${ }^{4-9}$ have addressed some commercial reactor sensitivities to confinement and beta, but these studies did not incorporate true optimization methods and were only able to examine a few parametric variations at time, while holding many other parameters constant.

Chapter 3 presents cases for the following reactor types:

- Steady-state tokamak reactors extrapolated from the TPX concept.

- Inductively driven pulsed tokamak reactors with otherwise comparable plasma assumptions as the steady-state cases.

- Inductively driven pulsed tokamak reactors that also assume plasma guidelines similar to those for the presently envisioned ITER Engineering Design Activity (EDA) device.

- Steady-state tokamak devices with no Troyon beta limit and only neoclassical confinement.

Table 2 lists these cases along with the motivating philosophy for examining them. For each reactor type, we parametrically show the impact on reactor potential of increasingly aggressive physics assumptions on confinement and beta-all using the same engineering design basis. All cases use conventional engineering and first-of-a-kind reactor costing. Also, we assume conventional current profile shapes, which may preclude some high bootstrap fraction possibilities. However, the ramifications of higher bootstrap fractions should be similar to those of cases we show with high current drive efficiencies. The steady-state reactor results show improvements in reactor concepts from advances in the physics data base. Such advances are anticipated in the proposed TPX experiment. ${ }^{1}$ These advanced steady-state results will be compared to those for pulsed inductive reactors using the reduced beta and confinement levels consistent with today's physics data base.

Results of this study can be used to identify the physics areas of highest leverage toward improving the tokamak reactor concept.

Some key results from this study are the following:

- A surprisingly narrow range of plasma confinement and beta are found to be useful in minimizing the COE for a tokamak reactor. Improvements in only one of these quantities is not useful beyond some point without accompanying improvements in the other.

- For the plasma beta limited by a Troyon coefficient $(g)$ near 4.3 (\% mT/MA), confinement levels characterized by $H$ factor enhancements (where $\tau_{E}=H^{*} \tau_{E, L}$, and where $\tau_{E, L}$ is the confinement time predicted by the ITER-89 L-mode scaling) of only 2 are useful for our nominal steady-state-driven tokamak. These confinement levels are similar to those observed in present-day experiments. If the permissible Troyon beta coefficient is near 6 , the useful $H$ factor confinement range increases to 2.5 , still close to present-day confinement levels. If the reactor embodiment is forced to use a higher confinement $H$ factor than optimum for a given Troyon beta coefficient, then the design will move to a less optimum point with a correspondingly higher COE. 
Table 1. Summary of the plasma and device constraints applied in this study

\begin{tabular}{|c|c|c|c|}
\hline Constraint & $\begin{array}{l}\text { Steady-state } \\
\text { reactor }\end{array}$ & $\begin{array}{l}\text { Pulsed } \\
\text { reactor }\end{array}$ & $\begin{array}{l}\text { ITER-like } \\
\text { reactor }\end{array}$ \\
\hline \multicolumn{4}{|l|}{ Physics } \\
\hline $\begin{array}{l}\text { Plasma power balance (with ITER-89 L mode } \\
\text { energy confinement) }\end{array}$ & $\mathbf{x}$ & $\mathbf{x}$ & $\mathbf{x}$ \\
\hline Troyon beta limit & $\mathbf{x}$ & $\mathbf{x}$ & $\mathbf{x}$ \\
\hline$q_{95} \geq 3$ & $\mathbf{x}$ & $\mathbf{x}$ & $\mathbf{x}$ \\
\hline$q_{0}=1.05$ & $\mathbf{x}$ & $\mathbf{x}$ & $\mathbf{x}$ \\
\hline$I_{\text {plasma }}=I_{\text {bootstrap }}+I_{\text {noninductive }}$ & $\mathbf{x}$ & & \\
\hline$(\mathrm{V}-\mathrm{s})_{\text {capability }} \geq(\mathrm{V}-\mathrm{s})_{\text {requirement }}{ }^{a}$ & $\mathbf{x}$ & $\mathbf{x}$ & $\mathbf{x}$ \\
\hline$I_{\text {plasma }} \geq$ minimum to confine alphas & $\mathrm{x}$ & $\mathbf{x}$ & $\mathbf{x}$ \\
\hline \multicolumn{4}{|l|}{ Magnets } \\
\hline $\begin{array}{l}\text { Toroidal field coils (TFC) conduit stress } \\
\leq 550 \mathrm{MPa}\end{array}$ & $\mathbf{x}$ & $\mathbf{x}$ & $\mathbf{x}$ \\
\hline TFC external case stress $\leq 550 \mathrm{MPa}$ & $\mathbf{x}$ & $\mathbf{x}$ & $\mathbf{x}$ \\
\hline TFC dump voltage $\leq 20 \mathrm{kV}$ & $\mathbf{x}$ & $\mathbf{x}$ & $\mathbf{x}$ \\
\hline TFC $I_{\text {operate }} / I_{\text {critical }} \leq 0.5$ & $\mathbf{x}$ & $\mathbf{x}$ & $\mathbf{x}$ \\
\hline TFC hot-spot temperature $\leq 150 \mathrm{~K}$ & $\mathbf{x}$ & $\mathbf{x}$ & $\mathbf{x}$ \\
\hline TFC temperature margin $\geq 2.5 \mathrm{~K}$ & $\mathbf{x}$ & $\mathbf{x}$ & $\mathbf{x}$ \\
\hline $\mathrm{OHC} J_{\mathrm{BOP}} \leq$ allowable & $\mathbf{x}$ & $\mathbf{x}$ & $\mathbf{x}$ \\
\hline $\mathrm{OHC} J_{\mathrm{EOF}} \leq$ allowable & $\mathbf{x}$ & $\mathbf{x}$ & $\mathbf{x}$ \\
\hline \multicolumn{4}{|l|}{ Device } \\
\hline $\begin{array}{l}\text { Inner shield thickness greater than or equal to } \\
\text { allowable }\end{array}$ & $\mathbf{x}$ & $\mathbf{x}$ & $\mathbf{x}$ \\
\hline $\begin{array}{l}\text { Inner divertor } \rightarrow \text { TFC distance greater than or } \\
\text { equal to allowable }\end{array}$ & $\mathbf{x}$ & $\mathbf{x}$ & $\mathbf{x}$ \\
\hline TFC ripple less than or equal to allowable & $\mathbf{x}$ & $\mathbf{x}$ & $\mathbf{x}$ \\
\hline Average neutron wall load $\leq 20 \mathrm{MW} / \mathrm{m}^{2}$ & $\mathbf{x}$ & $\mathbf{x}$ & $\mathbf{x}$ \\
\hline Area for injection power $<10 \%$ wall area & $\mathbf{x}$ & $\mathbf{x}$ & \\
\hline$P_{\text {net-electric }}=$ input requirement & $\mathbf{x}$ & $\mathbf{x}$ & $\mathbf{x}$ \\
\hline
\end{tabular}

$a_{\text {The volt-second requirement is different for the pulsed and steady-state reactors. }}$ 
Table 2. Reactor types examined in this study and motivating reasons for examining them

\begin{tabular}{|c|c|}
\hline Reactor type & Philosophy \\
\hline Steady state & $\begin{array}{l}\text { Reactor extrapolation potential from a TPX-based } \\
\text { set of plasma assumptions }\end{array}$ \\
\hline Inductively pulsed & $\begin{array}{l}\text { Reactor extrapolation potential, if the steady-state } \\
\text { current drive requirement is dropped and a mini- } \\
\text { mum inductive pulse length applied }\end{array}$ \\
\hline $\begin{array}{l}\text { Inductively pulsed, with ITER- } \\
\text { EDA-like plasma design } \\
\text { requirements }\end{array}$ & $\begin{array}{l}\text { Reactor extrapolation potential of a pulsed reactor } \\
\text { with ITER-EDA-like plasma guidelines }\end{array}$ \\
\hline $\begin{array}{l}\text { No beta limit, only neoclassical } \\
\text { confinement }\end{array}$ & $\begin{array}{l}\text { Ultimate steady-state tokamak reactor potential } \\
\text { with conventional engineering }\end{array}$ \\
\hline
\end{tabular}

- Increases in current drive efficiency reduce the $\mathrm{COE}$ by lowering the power recirculating fraction but do not significantly alter the useful range of confinement and beta.

- Operation at a high edge safety factor, $q_{95}$ (e.g., for second stability), results in a minimal increase on the COE.

- Inductively driven, pulsed reactors have somewhat increased useful ranges of confinement, relative to the steady-state cases. For a Troyon beta limit coefficient $g$ near 4.3, $H$ factors up to 2.5 are useful, and for $g$ near $6, H$ factors up to 3 are useful.

- The inductively driven, pulsed reactor performance is sensitive to the required pulse length. With comparable $H$ factor and $g$ levels, pulsed reactors offer a COE similar to steady-state cases if burn times near $5 \mathrm{~h}$ can be attained without significant penalty for energy storage and fatigue issues. Higher burn times tend to have a severe detrimental impact on the pulsed cases due to the volt-second requirements.

- The pulsed reactors tend toward high aspect ratio (4 to 5) to minimize the impact of supplying a large ohmic heating coil $(\mathrm{OHC})$, whereas the steady-state reactors optimize in the range of $A \sim 3$ to 4 .

- All reactor types are sensitive to the improvements in physics, in particular the attainable Troyon beta limit factor $g$. For example, operation with advanced physics $(H \leq 4$, $g<6$ ), compared to the present-day physics $(H \leq 2, g \leq 2.5)$, offers (1) about a factor of 2 reduction in the COE for constant unit plant size or (2) up to a reduction in 4 in the plant unit size (and cost) for the same COE. 


\section{MODELING}

\subsection{PHYSICS MODEL}

In general, we follow the global physics models widely used in reactor analysis. 5,10 For all cases shown, we employ global, ${ }^{*}$ volume-averaged transport models with profiles adjusted to match parabolic shapes for temperature and density [i.e., of the form $X(\rho)=$ $\left.\left(1-\rho^{2}\right)^{\alpha}\right]$. One area of our modeling that does differ from the usual reactor models is the incorporation of a fixed boundary magnetohydrodynamic (MHD) equilibrium calculation (see Ref. 3). This MHD equilibrium provides the relationship between the plasma current, the current profile, and the plasma geometry. This also means that the profile averaging (of terms used in the plasma power balance, for instance) is done over more realistic flux shapes than the usual nested ellipse approximation in global transport models. ${ }^{10}$ In this section we describe the nominal constraints and assumptions employed in all cases, unless otherwise stated. A list of the major device configurational assumptions is shown in Table 3.

\subsubsection{Impurity Ion Concentrations}

For impurity concentrations, we follow the ITER CDA guidelines ${ }^{10}$ for carbon, oxygen, and iron and assume a $10 \% n_{\alpha} / n_{\mathrm{e}}$ ratio (which typically results in a $Z_{\text {eff }} \sim 1.9$ ). All cases here assume a 50/50 D-T fuel mixture. Although we do include the D-D side reactions, this is a small effect. Our assumption of a constant ash fraction is somewhat simplistic. As confinement improves, it is likely that the ash fraction will increase.

\subsubsection{Plasma Power Balance}

For plasma power balance, a single fluid global power balance is used, which includes the effects of fusion power, auxiliary injection power, Bremsstrahlung radiation, synchrotron radiation, and plasma transport (see Appendix D of Ref. 10 for a detailed description of the terms used). Plasma transport losses are modeled with the usual global formulation employing an energy confinement time scaling:

$$
P_{\text {Transport }} \propto \frac{3 / 2 n<T\rangle}{\tau_{E}} .
$$

To calculate the energy confinement time $\left(\tau_{E}\right)$, we use an inverse quadrature combination of the ITER-89 Power scaling ${ }^{11}$ and neoclassical confinement: ${ }^{12}$

$$
\tau_{E}(s)=\sqrt{\left(\frac{1}{\tau_{\text {ITER }-89}}\right)^{2}+\left(\frac{1}{\tau_{\mathrm{NC}}}\right)^{2}},
$$

\footnotetext{
*SUPERCODE does have 1-1/2 dimensional transport capability, but we have chosen to use the global zero-dimensional physics models, which are more appropriate for large-scale device optimization studies.
} 
Table 3. Nominal plasma and device configurational assumptions

\begin{tabular}{|c|c|c|}
\hline & $\begin{array}{l}\text { TPX and pulsed } \\
\text { reactors }\end{array}$ & $\begin{array}{c}\text { ITER-EDA } \\
\text { reactor }\end{array}$ \\
\hline Configuration & Double null & Single null \\
\hline Elongation (x-point) & 2.0 & 1.6 \\
\hline Triangularity (x-point) $^{a}$ & $0.3<\delta<0.8$ & 0.35 \\
\hline Density profile exponent $\alpha_{n}$ & 0.5 & 0.5 \\
\hline Temperature profile exponent $\alpha_{T}$ & 1.0 & 1.0 \\
\hline \multicolumn{3}{|l|}{ Radial builds, m } \\
\hline $\mathrm{OHC} / \mathrm{TF}$ coil gap & 0.08 & $\leftarrow$ \\
\hline TF coil/vacuum vessel (VV) gap & 0.07 & $\leftarrow$ \\
\hline Inner vacuum vessel & 0.32 & $\leftarrow$ \\
\hline Inner breeding blanket zone & 0.19 & $\leftarrow$ \\
\hline First wall & 0.04 & $\leftarrow$ \\
\hline Inner/outer scrapeoff & 0.15 & $\leftarrow$ \\
\hline Outer breeding blanket zone & 0.25 & $\leftarrow$ \\
\hline Outer shield & 0.90 & $\leftarrow$ \\
\hline Outer vacuum vessel & 0.32 & $\leftarrow$ \\
\hline Outer VV/TFC gap $b$ & $\geq 0.25$ & $\leftarrow$ \\
\hline \multicolumn{3}{|l|}{ Vertical builds, m } \\
\hline Top scrapeoffc & 0.5 & $\leftarrow$ \\
\hline Shield on topd & 0.75 & $\leftarrow$ \\
\hline Divertor structure & 0.35 & $\leftarrow$ \\
\hline Gap & 0.25 & $\leftarrow$ \\
\hline $\begin{array}{l}\text { Divertor } \mathrm{x} \text {-point to strike-point } \\
\text { (outer/inner), } \mathrm{m}\end{array}$ & $1.5 / 0.7$ & $\leftarrow$ \\
\hline
\end{tabular}

$a_{\text {The triangularity is influenced by the inner divertor space requirement (see }}$

Sect. 2, this report).

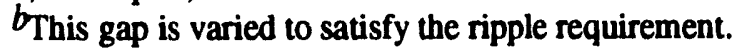

CUsed only for the single-null, ITER-like reactor case.

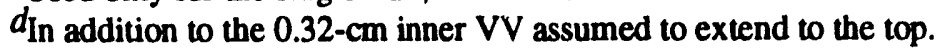

where

$$
\begin{aligned}
\tau_{\text {ITER-P }}(s) & =H 0.048 I_{p}^{0.85} R^{1.2} a^{0.3} \kappa_{\chi}^{0.5} n_{20}^{0.1} B^{0.2} A_{i}^{0.5} / P^{0.5} \\
\tau_{\mathrm{NC}}(s) & =0.375 f_{g} g_{\chi} a^{0.5} / \chi
\end{aligned}
$$

$I_{p}$ is the plasma current (MA), $R$ is the major radius (m), $a$ is the minor radius (m), $\kappa_{x}$ is the elongation, $n_{20}$ is the line-averaged electron density $\left(10^{20} \mathrm{~m}^{-3}\right), B$ is the field on axis (T), $A_{i}$ is the averaged fuel ion mass, and $P$ is the power deposited in the plasma (alpha power + injected power-Bremsstrahlung power) (MW). For the auxiliary injection power to the plasma $\left(P_{\text {aux }}\right)$ we include both the current drive power $\left(P_{\mathrm{cd}}\right)$ and any additional injection power that is used solely for heating the plasma $\left(P_{\text {heat }}\right)$. The value of the enhancement $H$ factor is varied parametrically. In the neoclassical confinement time, we 
evaluate the neoclassical diffusivity ${ }^{13} \chi\left(\mathrm{m}^{2} / \mathrm{s}\right)$ at the $80 \%$ flux surface, and the geometry factor is

$$
f_{g}=2 \kappa_{x}^{2} /\left(1+\kappa_{x}^{2}\right)
$$

The profile term (see Ref. 12) is

$$
g_{\chi}=\left[1-\rho_{80}\left(1+\alpha_{T^{+}} \alpha_{n}\right)\right] /\left[\alpha_{T}\left(1+\alpha_{T}+\alpha_{n}\right) \rho_{80}^{2}\left(1-\rho_{80}\right)^{\alpha_{T}+\alpha_{n}-1}\right]
$$

where $\rho_{80}$ is the normalized plasma radius at the $80 \%$ flux surface (see Ref. 12). We include the neoclassical confinement time in this fashion to ensure that confinement never gets better than that predicted by neoclassical for any value of the enhancement factor $H$ used with the empirical ITER-89 Power scaling. For all cases except the Ultimate reactors in Sect. 3.4, the confinement time is dominated by $\tau_{\text {TTER-P. }}$

\subsubsection{Maximum Beta}

The plasma beta is constrained to be within the Troyon beta limit ${ }^{14}$ by $\beta(\%) \leq$

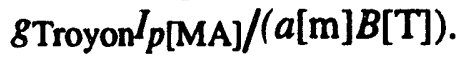

\subsubsection{MHD Requirements}

In the MHD analysis, we fix the safety factor on the axis at 1.0 and require the $95 \%$ flux surface safety factor $\left(q_{95}\right)$ to be constrained by $q_{95} \geq 3$. We do, however, show the sensitivity of using $995>5$.

\subsubsection{Current Drive}

In all steady-state cases, we require that $I_{p}=I_{B S}+I_{N I}+I_{B S}$ is the bootstrap current and is calculated with the Hirshman model. ${ }^{15} I_{N I}$ is the noninductively driven plasma current and is scaled as

$$
I(\mathrm{MA})_{N I}=c_{c d} 0.07<T_{\mathrm{e}}>_{n} /\left[\left(2+\mathrm{Z}_{\mathrm{eff}} n_{20} R\right] P_{c d}(\mathrm{MW}) .\right.
$$

Here $\left\langle T_{\mathrm{e}}\right\rangle_{n}$ is the density-weighted average plasma electron temperature, $P_{c d}$ is the current drive power, and $c_{c d}$ is a current drive efficiency enhancement factor, normally set to one, but varied parametrically to indicate the impact of current drive improvements. This is a simple scaling for ICH current drive from Ref. 10, and we use it here as a global scaling, characteristic of present-day capabilities. Also, we permit the current to be driven "backwards" if $I_{B S}>I_{p}$, but this condition never occurs for cases shown in this report.

\subsubsection{Alpha Confinement}

We also require that the plasma current be sufficient to confine most of the energetic alpha particles. This is accomplished by requiring: 16 


$$
I_{P} \geq 6.5 / A^{0.5} \kappa_{x}\left(1+2 \delta_{x}^{2}-1.2 \delta_{x}^{3}\right) / 2
$$

Here $\kappa_{x}$ and $\delta_{x}$ are the plasma elongation at the separatrix.

\subsubsection{Volt Seconds}

The volt-second requirement for the poloidal field (PF) coil set is specified by

$$
(\mathrm{V}-\mathrm{s})_{\mathrm{PF}} \geq(\mathrm{V}-\mathrm{s})_{\text {startup }}+(\mathrm{V}-\mathrm{s})_{\text {burn }} \text {, }
$$

where

$$
\begin{aligned}
(\mathrm{V}-\mathrm{s})_{\text {startup }}(\mathrm{Wb}) & =f_{\text {ind }} L_{p}(H) I_{p}(A)+C_{\text {Ejima }} \mu_{0} I_{p}(A) R(m)+(\mathrm{V}-\mathrm{s})_{\text {extra }}, \\
(\mathrm{V}-\mathrm{s})_{\text {burn }}(\mathrm{Wb}) & =\tau_{\text {burn }} V_{\text {loop }} .
\end{aligned}
$$

(See Ref. 10 for a description of the plasma inductance and loop voltage calculations.) For steady-state cases, we assume a predominantly noninductive startup scenario with only modest inductive assist, reflected by $f_{\text {ind }}=0.1, C_{\text {ejima }}=0$, and (V-s) extra $=0$. Also for steady state the loop voltage is zero, resulting in no burn requirement. For inductively driven pulsed reactor cases, we assume a full inductive plasma startup reflected by $f_{\text {ind }}=$ $1.0, C_{\text {ejima }}=0.5$, and (V-s)extra $=10(\mathrm{~Wb})$. The PF coil volt-second capability is calculated using PF coil currents at the beginning of the pulse (BOP) when the plasma current is initiated and at the end of full beta flattop (EOF). The PF coil volt-second capability [(V-s)PF] can be calculated as

$$
(\mathrm{V}-\mathrm{s})_{\mathrm{PF}}=\sum_{i=\mathrm{PF}-\text { Coils }} L_{i-\text { plasma }} I_{i-\mathrm{EOF}}-\sum_{i=\mathrm{PF}-\text { Coils }} L_{i-\text { plasma }} I_{i-\mathrm{BOP}} .
$$

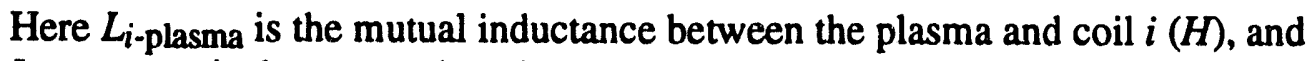

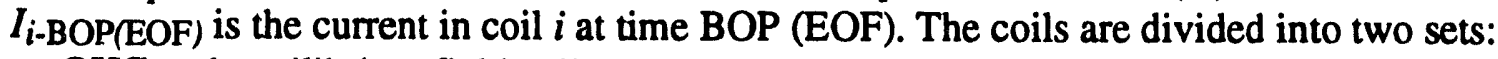
an OHC and equilibrium field coils. The current in the OHC at BOP and EOF is allowed to vary subject to the engineering constraints described in the section below. The equilibrium field coil currents at time BOP are calculated to null the PF across the plasma midplane. At time EOF, we calculate the currents in the vertical field coils (i.e., the PF coils with radius outside of the plasma) so that they provide the required equilibrium field $\left(B_{v}\right)$ at $R+a$ of

$$
B_{v}(\mathrm{~T})=0.1^{I}(\mathrm{MA}) / R(\mathrm{~m})\left[\ln (8 A)+1.46 \beta_{p}+l_{i} / 2+3 / 2\right]
$$

Currents in the other PF coils (those that primarily control the plasma shape near the $\mathrm{x}$-point) are assumed to scale at EOF as $0.4 I_{p}$. The actual currents in these coils are highly dependent on nuances in the plasma shape and profiles, and their calculation is outside the scope of a fixed boundary plasma model. However, the current in these "shaping coils" has little impact on the volt-second balance. 


\subsubsection{Divertor Heat Load}

We do not restrict the divertor heat load. We assume that a solution to the divertor power-handling problem will be found, which does not adversely affect the plasma confinement or beta.

\subsection{ENGINEERING CONSTRAINTS}

Many of the engineering models employed for this study were developed for, and calibrated to, the ITER CDA device. In this respect, we do not assume large extrapolations in the present-day technology base, as was done in the ARIES reactor study. ${ }^{5}$ The aim of this study is to address the impact of physics advances on reactors under the same set of conventional engineering constraints, rather than the impact of technology advances.

\subsubsection{TF Coils}

A cable-in-conduit $\mathrm{Nb}_{3} \mathrm{Sn}$ superconductor surrounded by an external case is assumed for the toroidal field (TF) coils (this is the coil concept adopted by the ITER CDA). Rather than employing a simple allowable J(B) model, we use the analysis of Ref. 17. In this model we require that

$$
\begin{gathered}
V_{\text {dump }} \leq 20 \mathrm{kV}, \\
I_{\text {operate }} / I_{\text {crit }} \leq 0.5, \\
T_{\text {hot-spot }} \leq 150 \mathrm{~K}, \\
\text { temperature margin } \geq 2.5 \mathrm{~K}, \\
\text { case stress } \leq 550 \mathrm{MPa}, \\
\text { conduit stress } \leq 550 \mathrm{MPa} .
\end{gathered}
$$

The dump voltage is

$$
V_{\text {dump }}(\mathrm{V})=\frac{2 W_{\mathrm{TF}}(\mathrm{J})}{\tau_{\text {dump }}(\mathrm{s}) I_{\text {operate }}(\mathrm{A})}
$$

We calculate the TF stored energy ( $W_{\mathrm{TF}}$ ) by integrating the TF across the TF coil and its bore, with the coil shape consistent with the configurational assumptions listed in Table 1. The critical current and temperature margins are calculated following the prescription in Ref. 17, assuming a net strain in the conductor of -0.005 and a temperature at the peak field location of $5 \mathrm{~K}$. The temperature rise during a quench ( $T_{\text {hot-spot }}$ is also calculated following the methods of Ref. 17. The case and conduit stress levels are calculated at the inboard midplane by a "5-ring" model, ${ }^{18}$ which approximates the case as the inner two rings and the cable area as the outer three rings. Simple force balance is used for each 
ring with the boundary condition that the radial stress is zero at the outer radii (i.e., wedged coils) to provide the average stresses in the radial and toroidal directions for the case and conduit. The vertical separating loads are subsequently combined with these in a Tresca combination. We limit these stresses to $550 \mathrm{MPa}$, which is lower than the $800 \mathrm{MPa}$ used in the detailed engineering of the ITER CDA, to allow for peaking and out-of-plane effects not included here.

\subsubsection{OH Coil}

The current density in the central solenoid (or $\mathrm{OHC}$ ) is constrained by 18

$$
J_{\mathrm{OH}}\left(\mathrm{A} / \mathrm{m}^{2}\right)=\frac{1.45 \times 10^{8}}{1+\frac{32 F_{g}\left(B_{i}+B_{0}\right)\left(r_{i}+r_{\mathrm{o}}\right)}{\sigma_{a l w}}+\frac{0.0216 \sqrt{B_{i}}}{\left(1-B_{i} / 23\right)^{2}\left[1-\frac{1}{16\left(1-B_{i} / 23\right)-5}\right]}} .
$$

Here $\sigma_{a l w}$ is the allowable stress (taken to be $330 \mathrm{MPa}$ here, typical for a structural material at cryogenic temperatures subject to a fatigue limit), $B_{i(0)}$ is the field at the inner (outer) surface of the solenoid $(\mathrm{T}), r_{i(0)}$ is the radius to the inner (outer) surface $(\mathrm{m})$, and $F_{g}$ is a geometry factor given by

$$
F_{g}=1+0.925 \frac{r_{i}}{r_{0}}-0.53\left(\frac{r_{i}}{r_{0}}\right)^{2} .
$$

This equation is apprupriate for a $\mathrm{Nb}_{3} \mathrm{Sn}$ cable-in-conduit solenoid. The first term in the denominator accounts for copper and helium space, the second term accounts for structure, and the final term accounts for the superconductor space requirements. When applying this formula, we calculate the field at the coil, including both the self field and the fields produced by the other PF coils and plasma.

\subsubsection{TF Ripple}

The outer TF coil return leg location is determined by the TPX ripple specification for the midplane ripple:

$$
\delta_{\text {peak-to-average }}(\%) \leq \frac{a}{\left(N_{\mathrm{TF}} q_{95} R\right)^{0.6}} \frac{\sqrt{\frac{1+\kappa_{95}^{2}}{2}}}{\sqrt{0.36+0.64 \kappa_{95}^{2}}}\left(\frac{R+a}{R+0.8 a}\right)^{N_{\mathrm{TF}}} .
$$

Here $N_{\mathrm{TF}}$ is the number of TF coils (taken to be 16 for all cases), $\mathrm{k} 95$ is the $95 \%$ flux surface elongation, $R$ is the major radius (in meters), and $a$ is the minor radius (in meters). 


\subsubsection{Shielding}

The builds are specified in Table 3, but we do vary the shield thickness to provide a constant fluence of neutrons to the TF coils. The total effective shielding thickness ( $\left.d_{\text {shield }}^{*}\right)$ is taken to be the first-wall thickness plus the vacuum vessel thickness plus the blanket thickness plus the shield thickness. By (1) approximating the neutron attenuation as exponential with an average e-fold distance of $0.07 \mathrm{~m}$ (for a stainless steel/water mixture), and (2) requiring $0.965 \mathrm{~m}$ of shielding for a fluence of $3 \mathrm{MW}-\mathrm{a} / \mathrm{m}^{2}$, we get:

$$
d_{\text {shield }}^{*}(\mathrm{~m}) \geq 0.965+0.07 \ln \left(\Gamma T_{\text {life }} f_{\text {cap }} / 3\right) \text {. }
$$

Here $\Gamma$ is the neutron wall load $\left(\mathrm{MW} / \mathrm{m}^{2}\right), T_{\text {life }}$ is the plant life (years) (assumed to be 30 years), and $f_{\text {cap }}$ is the average plant operating capacity (assumed to be $75 \%$ ).

\subsubsection{Inner Divertor Space}

Divertor design is problematic in high-power tokamaks, and a common difficulty in tokamak design is providing adequate room on the inboard side for the inner divertor field lines and the divertor structure. Based on shielding requirements from the ITER CDA, we require that the distance from the inner divertor strike point to the TF coil $\left(d_{s t k-\mathrm{TF}}\right)$ be constrained by

$$
\left(d_{\text {stk-TF }}\right) \geq 1.55 \mathrm{~m}
$$

to allow room for shielding, vacuum vessel, divertor structure, and a cryostat. The plasma inboard scrapeoff and triangularity are allowed to vary to satisfy this, subject to the bounds shown in Table 3. Also, we assume a distance in the poloidal plane of $0.7 \mathrm{~m}$ between the $x$-point and the plasma strike point (same as the ITER CDA), to provide room for some decrease of the plasma scrapeoff temperature.

\subsubsection{Injection Power Limit}

We allow the auxiliary injection power (for plasma heating and current drive) to vary as best determined by the overall optimization process. To ensure that the injection power space requirements do not have too strong an impact on the blanket breeding area, we require that the area facing the plasma dedicated to injection power $\left(A_{\text {injector }}\right)$ be limited to

$$
A_{\text {injector }} \leq 0.1 A_{f w},
$$

where $A_{f w}$ is the first wall area; an injector power density of $20 \mathrm{MW} / \mathrm{m}^{2}$ is assumed.

\footnotetext{
*The shielding distance of $0.965 \mathrm{~m}$ is $12.5 \mathrm{~cm}$ greater than that in the ITER-CDA device. This extra shielding was estimated to be needed to reach a fluence of $3 \mathrm{MW}-\mathrm{a} / \mathrm{m}^{2}$.
} 


\subsubsection{Wall Load Limit}

An upper limit of $20 \mathrm{MW} / \mathrm{m}^{2}$ is imposed on the average neutron wall load. Loads higher than this would impose first wall design requirements well beyond the present capabilities. Also, operation at wall loads above this level would adversely affect the plant availability because of the excessive wall/blanket changeouts due to material damage effects. This bound is never met for any cases in this study; the maximum wall load is determined by other physics or engineering constraints.

\subsection{REACTOR MODELING}

This section describes the models used in reactor power flow and COE calculations. These models have been developed previously, and we follow the generally accepted practice. More detailed descriptions of the terms used here may be found in Refs. 4 and 5 . Table 4 lists many of the important assumptions used in the Reactor/COE calculations, along with the corresponding values used in the Generomak ${ }^{4}$ and ARIES-15 study.

Table 4. Assumptions used in the plant power balance and cost of electricity calculation

\begin{tabular}{|c|c|c|c|}
\hline & This study & Generomak & ARIES-1 \\
\hline \multicolumn{4}{|c|}{ Plant power balance } \\
\hline Thermal $\rightarrow$ electric efficiency & 0.4 & 0.36 & $0.49^{a}$ \\
\hline Nonneutron power $\rightarrow$ thermal power, $\%$ & 70 & 70 & 100 \\
\hline Blanket energy gain & 1.30 & 1.14 & 1.30 \\
\hline $\begin{array}{l}\text { Injector power efficiency, wall plug } \rightarrow \text { plasma } \\
\text { efficiency, } \%\end{array}$ & 72 & & 71 \\
\hline \multicolumn{4}{|c|}{ Costing assumptions } \\
\hline Construction time (years) & 6 & 8 & 6 \\
\hline Plant life (years) & 30 & 30 & 30 \\
\hline Average capacity factor, $\%$ & 75 & 65 & 76 \\
\hline Indirect plus contingency cost factor, $\%$ & 55 & 50 & 45 \\
\hline Fixed charge rate $b\left(F_{\mathrm{CR} 0}\right)$ & 0.0966 & 0.10 & 0.0966 \\
\hline Effective cost of money $\left(\mathrm{year}^{-1}\right)^{c}$ & 0.0605 & 0.09 & 0.0435 \\
\hline Inflation rate $\left(\text { year }^{-1}\right)^{c}$ & 0.05 & 0.05 & 0.06 \\
\hline Direct cost & $\begin{array}{l}\text { First-of-a- } \\
\text { kind }^{d}\end{array}$ & $\begin{array}{l}\text { Tenth-of-a- } \\
\text { kind }\end{array}$ & $\begin{array}{l}\text { Tenth-of-a- } \\
\text { kind }\end{array}$ \\
\hline
\end{tabular}

$a_{\text {Assumes a high-temperature helium cooling system. }}$

$b_{\text {Constant dollar. }}$

$c$ We input the fixed charge rate $\left(F_{\mathrm{CR} 0}\right)$ independent from this value. The cost of money and inflation are used only for estimating the capitalization factor $\left(f_{\text {cap }}\right)$.

$d$ See Appendix A. This calculation is based on the ITER-CDA direct cost. This method results in direct costs approximately twice those reported using tenth-of-a-kind methods. 


\subsubsection{Reactor Power Balance}

In calculating the net electrical power generation we follow the power flow model of ARIES-1.5 The net electrical power generated is calculated as

$$
P_{\text {net }}=P_{\text {gross }}-P_{\text {recirc }} \text {. }
$$

where

$$
P_{, \text {oss }}=\eta_{\text {thermal }}\left\{f_{+\rightarrow \text { elec }} P_{\text {non-neutron }}+P_{\text {neutron }}+0.9 P_{\text {pump }}\right\},
$$

and $f_{+} \rightarrow$ elec is the fraction of non-neutron power converted to high-grade heat (we take this fraction to be $70 \mathrm{vs} 100 \%$ in the ARIES-1 study 5 ), $P_{\text {non-neutron }}$ is the fusion alpha power plus the auxiliary injection power, $P_{\text {neutron }}$ is the neutron power in the blanket and shield ( $=0.8 P_{\text {fusion }} E_{\text {mull }}$ ), and $\eta_{\text {thermal }}$ is the thermal-to-electric conversion efficiency ( $40 \%$ here). $P_{\text {pump }}$ is the primary coolant loop pumping power deposited in the heat transport system and is calculated (following Ref. 5) as

$$
P_{\text {pump }}=\left[f_{+\rightarrow \text { elec }} P_{\text {non-neutron }}+P_{\text {neutron }}\right] \frac{f_{\text {pump }}}{1-f_{\text {pump }}},
$$

with $f_{\text {pump }}$ taken to be 0.025 . This pumping power is for a high-temperature heliumcooled system, consistent with the relatively high thermal-to-electric conversion efficiency used here. The recirculating power is scaled as

$$
P_{\text {recirc }}=\frac{P_{\text {aux }}}{\eta_{\text {inject }}}+P_{\text {pump }}+P_{\text {BOP }}
$$

where the $P_{\text {aux }}$ is the auxiliary power (both current drive and heating only) to the plasma, $\eta_{\text {inject }}$ is the wall plug to injector efficiency ( $72 \%$ here), and $P_{\mathrm{BOP}}$ is the recirculating power to run the balance of plant. We scale $P_{B O P}$ to reflect the relatively smaller fraction recirculated for larger power levels by

$$
P_{\mathrm{BOP}}=\min \left\{\begin{array}{c}
0.06 /\left(\frac{P_{\mathrm{gross}}(\mathrm{MW})}{1250}\right)^{0.6} . \\
1 / 3
\end{array}\right.
$$

We apply a constraint-requiring operation at a fixed electrical output, which is nominally $1000 \mathrm{MW}(\mathrm{e})$ :

$$
P_{\text {net }}[\mathrm{MW}]=1000 \text {. }
$$




\subsubsection{Cost of Electricity}

We use the Generomak ${ }^{4}$ methodology to perform the COE calculation. This is the basis of recent fusion reactor modeling. $4,5,19$ The detailed description of the COE calculation is described in Ref. 4, and we provide only an overview here. Some of the key assumptions are listed in Table 4. The COE at the grid (using constant 1990 dollars) is defined as

$$
\mathrm{COE}(\text { mills } / \mathrm{kWh})=\frac{C_{\mathrm{C} 0} F_{\mathrm{CR} 0}+C_{\mathrm{fuel}}+C_{\mathrm{O \& M}}}{8.76 \times 10^{-3} P_{\text {net }}(\mathrm{MW}) f_{\mathrm{av}}}
$$

$P_{\text {net }}$ is the net electric power generated (in megawatts), and $f_{\mathrm{av}}$ is the equivalent plant availability at full power. $C_{\mathrm{CO}} F_{\mathrm{CR} 0}$ is the capital cost portion of the $\mathrm{COE}$, where $C_{\mathrm{C} 0}$ is the constant dollar capital investment cost $(\$ M)$, and $F_{C R 0}$ is the constant dollar fixed charge rate $\left(0.0966\right.$ here). $C_{\text {fuel }}$ is the fuel portion of the COE, and $C_{O \& M}$ is the operation and maintenance portion of the COE.

\subsubsection{Capital Cost}

Fusion reactors tend to be large, capital intensive power sources, so the capital cost portion tends to dominate the COE. Unfortunately, calculation of the capital costs of large devices that have never been built is uncertain. The basis of our cost estimate is a model $^{20}$ for the direct cost that was developed for modeling the ITER-CDA device. This model is normalized to the direct cost estimate for the ITER CDA, which did not include any research and development (R\&D) costs but was a first-of-a-kind device. The scalings used in the direct cost are described in Appendix A.

This model was developed for a first-of-a-kind reactor cost, and the direct costs from this model tend to be greater than cost estimates of comparable devices using tenthof-a-kind discounting factors $4,5,9$ (see also Ref. 19 for a comparison of reactor costing methods). The actual cost benefit in building future fusion reactcrs to be gained from learning experience is uncertain, and we do not include these discounting factors. As such, our costing method results in higher direct costs (hence COE) relative to those based on tenth-of-a-kind devices. The magnitude of the learning curve cost reduction factors applied in previous reactor studies varies. For instance, Ref. 5 takes a 50\% credit for learning experience for all non-balance-of-plant related items (and results in direct costs roughly half of those arrived at here). The STARFIRE ${ }^{9}$ and MARS $^{21}$ studies applied different learning curve reduction factors to each account. In the case of the MARS study, this amounted to only a $17 \%$ net reduction in the direct cost from tenth-of-a-kind learning benefits. We note that although our costing method is based on the ITER-CDA costing method (i.e., a first-of-a-kind device), this procedure neglects some of the costs normally associated with a first-of-a-kind device such as engineering and R\&D (see Appendix A). In any case, we wish to stress relative cost differences in this report.

The constant dollar capital cost is calculated from the direct cost as

$$
C_{\mathrm{C} 0}=f_{\text {cap } 0} C_{\text {direct }} f_{\text {ind }} \text {, }
$$


where $f_{\text {cap } 0}$ is the constant dollar capitalization factor (see Ref. 4 for a derivation), $C_{\text {direct }}$ is the direct cost, and $f_{\text {ind }}$ is the indirect cost factor ( 0.55 here). We use a 6-year construction time, a $5 \%$ inflation rate, and a $6.05 \%$ average cost of money in calculating the constant dollar capitalization factor $f_{\text {cap } 0}$ (1.037).

\subsubsection{Fuel Costs}

$C_{\text {fuel }}$ includes (1) an average annual blanket/first-wall replacement cost, (2) annual fuel cost (for the D and $\mathrm{Li}$ ), and (3) a waste charge portion. The calculation of the COE portion for the blanket/first-wall replacement costs follows the method used in Ref. 4, and we use a fluence of $20 \mathrm{MW}-\mathrm{a} / \mathrm{m} 2$ to calculate the blanket/first-wall lifetimes. We emphasize that this is an assumed limit for prospective advanced materials for the 21 st century. Today's materials might be expected to last only $\sim 5-10 \mathrm{MW}-\mathrm{a} / \mathrm{m} 2$. The annual fuel costs, also taken from Ref. 4 , and inflated to 1989 dollars are $\left(0.51+30.5 F_{\text {CR0 }}\right)$ million dollars. The waste charge is equivalent to a $1 \mathrm{mill} / \mathrm{kWh}$ surcharge.

\subsubsection{O\&M Costs}

The operation and maintenance (O\&M) portion of the COE is calculated as 22

$$
C_{\mathrm{O} \& \mathrm{M}}(\$ \mathrm{M})=74.4 \sqrt{P_{\text {net }}(\mathrm{MW}) / 1200}
$$

\subsection{SOLUTION METHOD}

The above sections describe a formidable set of both equality and inequality constraints that, unless stated otherwise, are always required to be satisfied. These constraints are summarized in Table 1. Our goal is to find a unique solution (i.e., a set of tokamak physics and engineering parameters) that satisfies these constraints. To this end, we allow many of the tokamak parameters to vary, and we search for the combination of these that satisfies the above constraints and also results in the minimum COE. We treat the constraints described in the above sections as a simultaneous set of nonlinear equations and use standard optimization methods to find solutions. The default variables (and their bounds) used in the solution process are listed in Table 5.

Using this technique alleviates the need to make a priori assumptions for quantities such as the best aspect ratio, peak field, plasma operating temperature, etc. We stress that for all the trades we show, unless otherwise stated, all the quantities listed in Table 5 are allowed to vary, and all the constraints listed in Table 1 are required to be satisfied. 
Table 5. Quantities used as variables in the solution process ${ }^{a}$

\begin{tabular}{|c|c|c|}
\hline Variable quantity & $\begin{array}{l}\text { Lower } \\
\text { bound }\end{array}$ & $\begin{array}{l}\text { Upper } \\
\text { bound }\end{array}$ \\
\hline \multicolumn{3}{|c|}{ Physics } \\
\hline \multicolumn{3}{|l|}{ Plasma temperature } \\
\hline \multicolumn{3}{|l|}{ Plasma density } \\
\hline \multicolumn{3}{|l|}{ Plasma current } \\
\hline Current drive power, MW & 0 & \\
\hline Heating only power, MW & 0 & \\
\hline Triangularity & 0.3 & 0.8 \\
\hline \multicolumn{3}{|c|}{ Overall device } \\
\hline \multicolumn{3}{|l|}{ Major radius } \\
\hline \multicolumn{3}{|l|}{ Minor radius } \\
\hline \multicolumn{3}{|l|}{ Field on axis } \\
\hline \multicolumn{3}{|l|}{ Inner shield thickness } \\
\hline Inner scrapeoff, m & 0.15 & \\
\hline Outer TF/shield gap, $m$ & 0.10 & \\
\hline \multicolumn{3}{|c|}{ TF coil } \\
\hline \multicolumn{3}{|l|}{ Overall current density } \\
\hline Conduit thickness, mm & 0.1 & 10 \\
\hline External case thickness, $\mathrm{m}$ & 0.03 & \\
\hline Current per turn, kA & & 60 \\
\hline Conductor copper fraction & 0.1 & 0.9 \\
\hline Dump time, $s$ & 1 & \\
\hline \multicolumn{3}{|l|}{ TF coil total thickness } \\
\hline \multirow{2}{*}{\multicolumn{3}{|c|}{$\begin{array}{l}\mathrm{OH} c \\
\text { Current density at BOP }\end{array}$}} \\
\hline & & \\
\hline \multicolumn{3}{|l|}{ Current density at EOF } \\
\hline Hole in middle, $m$ & 0.1 & \\
\hline Winding thickness, $\mathrm{m}$ & 0.05 & \\
\hline
\end{tabular}

$a_{\text {Where applicable, the upper and lower bounds imposed }}$ for physical reasons are given. 


\section{RESULTS}

The primary goal of this study is to identify the areas of physics improvements that have the largest impact on making a tokamak reactor more attractive. By "impact" we mean reducing the $\mathrm{COE}$. The two primary physics considerations in reactor design are energy confinement and attainable beta. For the energy confinement consideration, we take the energy confinement enhancement factor (i.e., $H$ factor) needed to maintain plasma power balance as a parameter indicative of the confinement requirements. As noted above, we use the ITER-89 Power scaling for calculating the energy confinement time. For the beta consideration, we use the coefficient in the Troyon beta scaling $(g)$ as the measure for required beta level.

\subsection{STEADY-STATE REACTORS}

As a first example, we consider steady-state tokamak reactors, with the plasma current driven noninductively. These cases are illustrative of reactor types that might be extrapolated from the TPX experiment. ${ }^{1}$ Because the mission of the TPX device is to identify advanced physics operating regimes, these results serve to quantify the value of information expected from the TPX experiment. That is, the COE reductions observed here, with improved plasma confinement and beta levels, are the potential benefits of the TPX experiment.

\subsection{1 $(H, g)$ Space}

As an example, we consider the steady-state reactor at $1000 \mathrm{MW}(\mathrm{e})$. Figure 1(a) shows contours of minimum COE in $\left(H_{\max }, g_{\max }\right)$ space-henceforth referred to as $(H, g)$ space. At each $(H, g)$ grid point, we solve for the optimum steady-state reactor design at $1000 \mathrm{MW}(\mathrm{e})$ by allowing all reactor design variables listed in Table 5 to simultaneously optimize to minimize the COE. The "max" subscript on $H$ and $g$ means that these are maximum values. That is, at each $H_{\max }$ point, we require the actual $H$ value to be less than or equal to $H_{\text {max. }}$ It is apparent that the COE does not decrease for every increasing $H_{\max }$ and $g_{\max }$ level. The thick solid line is the maximum useful Troyon coefficient. Above this line, the COE contours turn vertical (i.e., the COE becomes independent of $\left.g_{\max }\right)$. Similarly, the dotted line is the maximum useful energy confinement time enhancement factor, ${ }^{*}$ and to the right of it, the COE contours are independent of $H_{\max }$. Thus, the useful region of $(H, g)$ space is the relatively narrow band between the thick solid line and dotted line in Fig. 1(a).

At first glance this result is somewhat surprising - that is, that a continually increasing level of energy confinement or beta is not necessarily beneficial in reducing the COE. To understand why, consider the variation of $\beta$ at a fixed normalized beta value (i.e., fixed $g$, where $\left.\beta \propto g I_{p} / a B\right)$. Using $I p \propto a B / A q f(\kappa, \delta, A), \beta \sim 1 / A$, at constant plasma shape, edge $q$ and $g$. Thus, with increasing $H$, the product $n T$ can only increase at the expense of higher $B$ or lower $A$. Lowering $A$ tends to reduce the amount of space

\footnotetext{
${ }^{*}$ The maximum useful $H$ and $g$ curves were found by scanning the minimum COE vs $g$ (with no limit on $H$ ) and scanning the minimum COE vs $H$ (with no limit on $g$ ), respectively.
} 


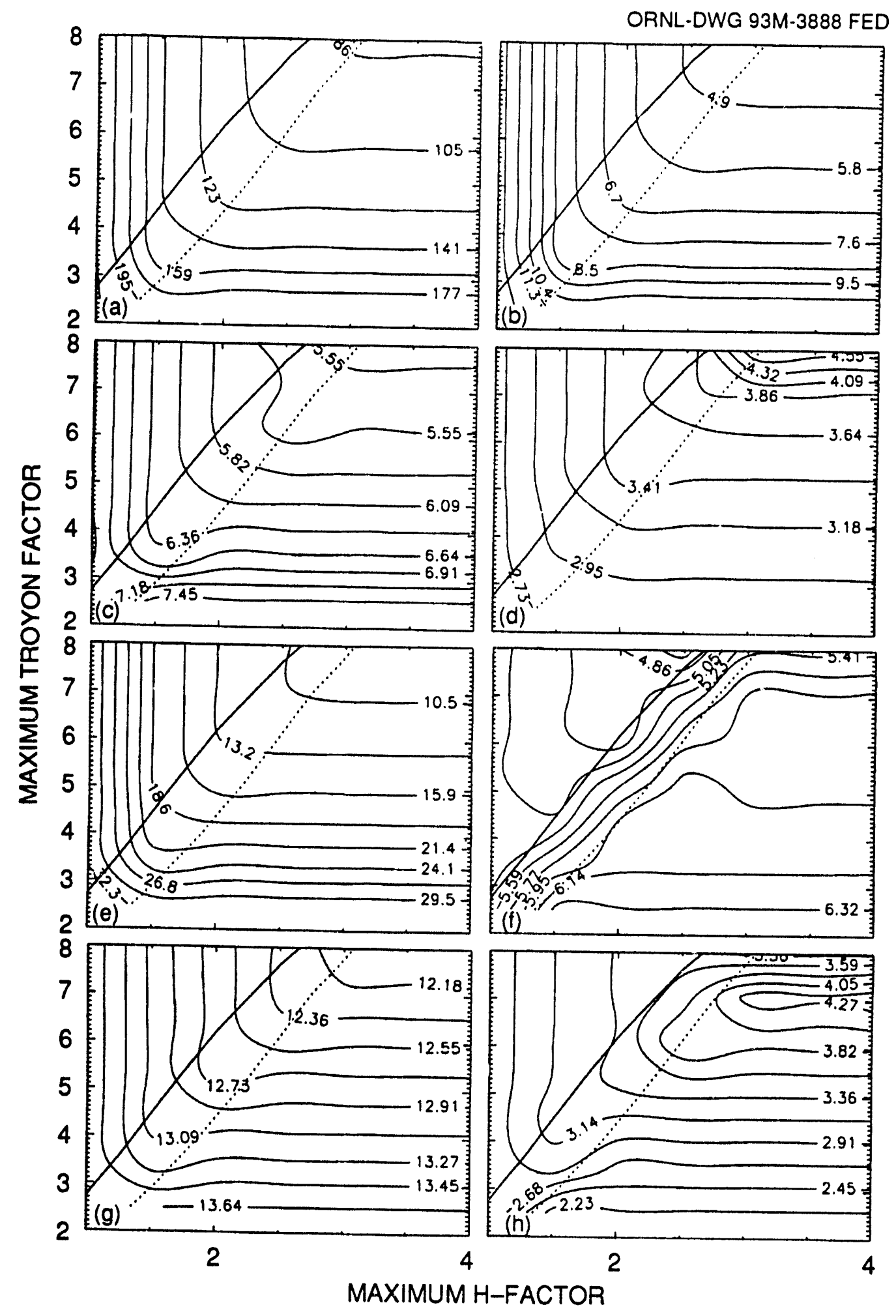

Fig. 1. Minimum COE steady-state reactor parameters in $(H, g)$ space. (a) COE (mills/kWh), (b) major radius $(\mathrm{m}),(c)$ capital cost $\left(\$ \times 10^{9}\right),(d)$ aspect ratio, $(e)$ plasma current (MA), $(f)$ field on axis $(T),(g)$ peak field at TFC $(T)$, and $(h)$ average neutron wall load $\left(\mathrm{MW} / \mathrm{m}^{2}\right)$. The thick solid line is the maximum useful Troyon $g$ curve, and the dotted line is the maximum useful confinement $H$ factor curve. 
available for the magnets (hence tending to reduce $B$ ). Thus, at a fixed $g$, it becomes uneconomical to simultaneously achieve higher $H$ values beyond some point because of the associated penalty of having to provide higher field levels. Forcing the reactor to use higher confinement $H$ factors than the optimum at a given Troyon beta coefficient results in a design with a higher COE.

Moving toward higher normalized beta values $(g)$ at a constant $H$ value results in lower plasma current levels needed to provide the necessary beta (aspect ratio varies only slightly). Because the achievable $T n \tau$ scales approximately as $\left(H I_{p} A\right)^{2}$ (see Ref. 10) for the ITER-89 Power scaling, this means additional injection power is needed to maintain power balance. This has a detrimental effect on the plant recirculating energy fraction. At the maximum useful $g$, the recirculating fraction cannot afford to go any higher.

The data from Fig. 1 can be replotted in an illustrative way to emphasize the above effect. In Fig. 2, the variation of the $H$ factor actually used vs the maximum allowable $H$ factor is shown for several $g$ levels. For Troyon coefficients limited to $\leq 4.3$, the region of useful confinement $H$ factors is $H \leq 2$, which is roughly within the presently observed $H$-mode regime. To beneficially use confinement levels much higher than this (say $H$ near 2.5) requires the simultaneous achievement of $g$ levels $>6$ with an edge $q_{95}$ of 3 . This indicates that there is more room for improving reactors by increasing presently achievable beta levels (near $g=3$ ) than from increasing present confinement levels (near $H=2$ ). We also note that there is a diminishing return of reducing the $\mathrm{COE}$ as one moves

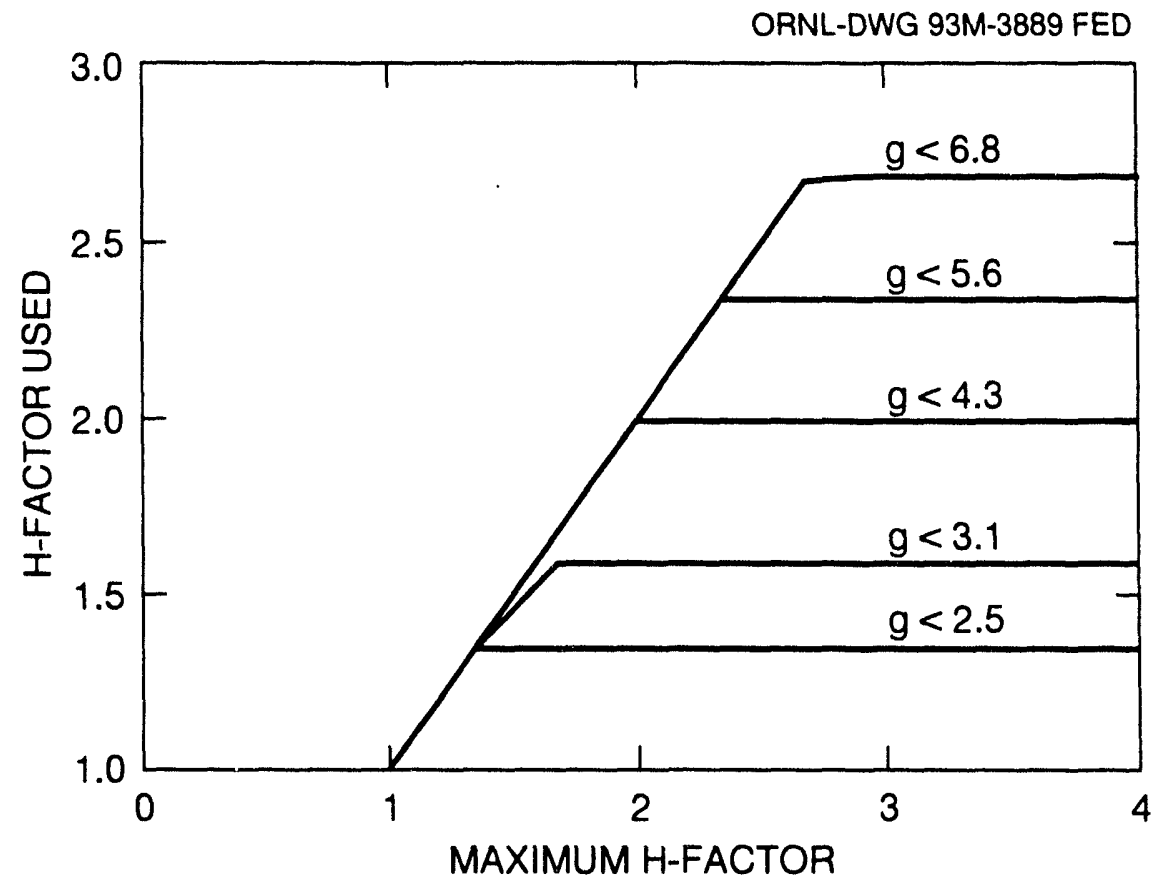

Fig. 2. Variation of useful ITER-89 confinement scaling $H$ factor vs the maximum allowed $H$ factor, for various Troyon beta limit coefficients $g$, for the nominal steadystate reactor. 
upward along the useful $(H, g)$ space [see Fig. 1(a)]. Increasing the $g$ from 3 to 5 results in $-30 \%$ COE reductions, whereas increasing $g$ from 5 to 7 provides only a further $20 \%$ COE reduction.

Some other optimum device and plasma parameters associated with the minimum COE optimum points are shown in Fig. $1(b)-(h)$. As one moves from the lower left region of the $(H, g)$ space to the upper region of useful $(H, g)$, there is a drop in the needed plasma current from roughly 25 to $10 \mathrm{M} \therefore$, accompanied by an increase in aspect ratio from roughly 3 to 4 . Also, as one moves to higher $(H, g)$ levels, the required drive power decreases. To reach a point with the plasma energy multiplication $Q$ (fusion power/injection power) $>20$, an $H>2.5$ and $g>6$ are needed.

With regard to the magnitude of the COE results here and in the following sections, we reiterate that these are calculated using first-of-a-kind cost methods. This method results in higher COE levels than methods taking tenth-of-a-kind learning curve benefits. However, it is the relative cost changes we wish to stress in addressing the impact of physics improvements on tokamak reactors.

\subsubsection{Current Drive Efficiency}

Figure 3(a) shows the minimum COE contours in $(H, g)$ space for 1000-MW(e) reactors with increased current drive efficiency (three times greater than the nominal efficiency described above). The primary difference is a lower $\mathrm{COE}$ for a given $(H, g)$ point, the effect being more pronounced at lower $(H, g)$ levels. Also, the maximum useful $g$ curve has dropped closer to the maximum useful $H$ curve because there is less advantage in going to smaller devices with higher injection powers for this case. However, the maximum useful $H$ curve for this case is similar to that of the nominal steady-state reactor in Fig. 1(a). The reactor costs, size, and plasma currents [see Fig. 3(b)-(h)] are also reduced relative to the nominal case of Sect. 3.1.1.

\subsubsection{Economy of Scale}

All cases presented thus far have been for a net electric power generation of $1000 \mathrm{MW}(\mathrm{e})$. Figure 4(a) shows the minimum COE vs the base electric power level for three different choices of physics performance: ${ }^{*}(1)$ present physics ${ }^{\dagger}(H \leq 2, g \leq 2.5)$, (2) modest physics improvements $(H \leq 3, g \leq 4)$, and (3) advanced physics ( $H \leq 4$, $g \leq 6$ ) -all with a lower bound on the edge $q_{95}$ of 3 (which is always hit). In this set of runs, the beta limit we chose was always hit, and the $H$ factor limit was never met. Some other device parameters associated with these cases are shown in Fig. $4(b)-(d)$ and are listed in Table 6. The usual reduction in COE for increased base loads is observed, most noticeably for the present-day physics level case, which has the highest capital cost. All cases have high recirculating power fractions due to the injection power required to

\footnotetext{
*We use these three levels of allowable $H$ and $g$ to characterize the degree of physics improvements throughout the rest of this report.

tThat is, presently achieved physics performance that would be sustainable in a nontransient manner in a conservatively designed system.
} 


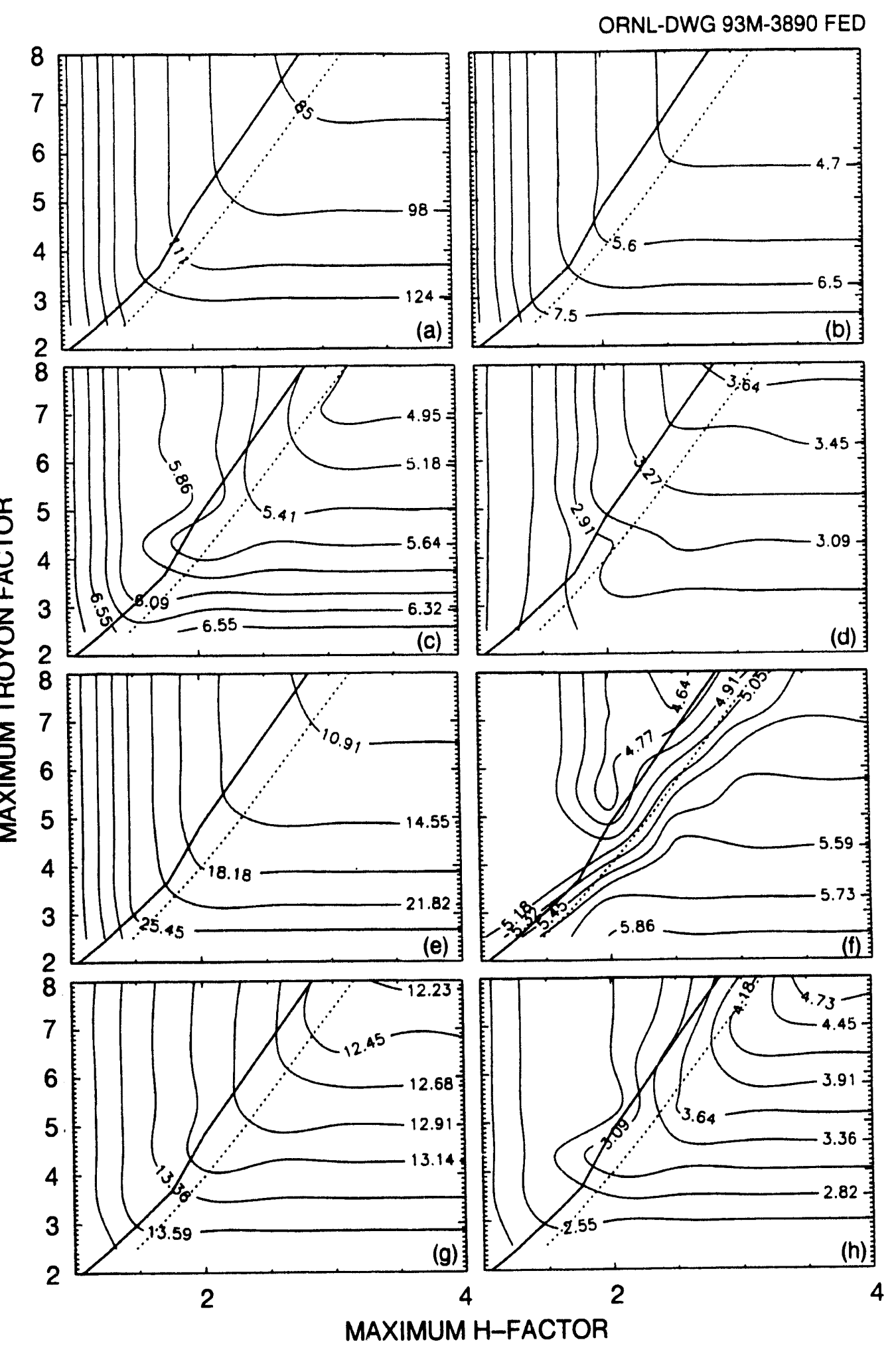

Fig. 3. Minimum COE steady-state reactor parameters in $(H, g)$ space with current drive efficiency improved by a factor of 3. (a) COE (mills $/ \mathrm{kWh}$ ), (b) capital cost $\left(\$ \times 10^{9}\right),(c)$ major radius $(\mathrm{m}),(d)$ aspect ratio, $(e)$ plasma current $(\mathrm{MA}),(f)$ field on axis $(\mathrm{T}),(g)$ peak field at TFC $(\mathrm{T})$, and $(h)$ average neutron wall load $\left(\mathrm{MW} / \mathrm{m}^{2}\right)$. The thick solid line is the maximum useful Troyon $g$ curve, and the dotted line is the maximum useful confinement $H$ factor curve. 

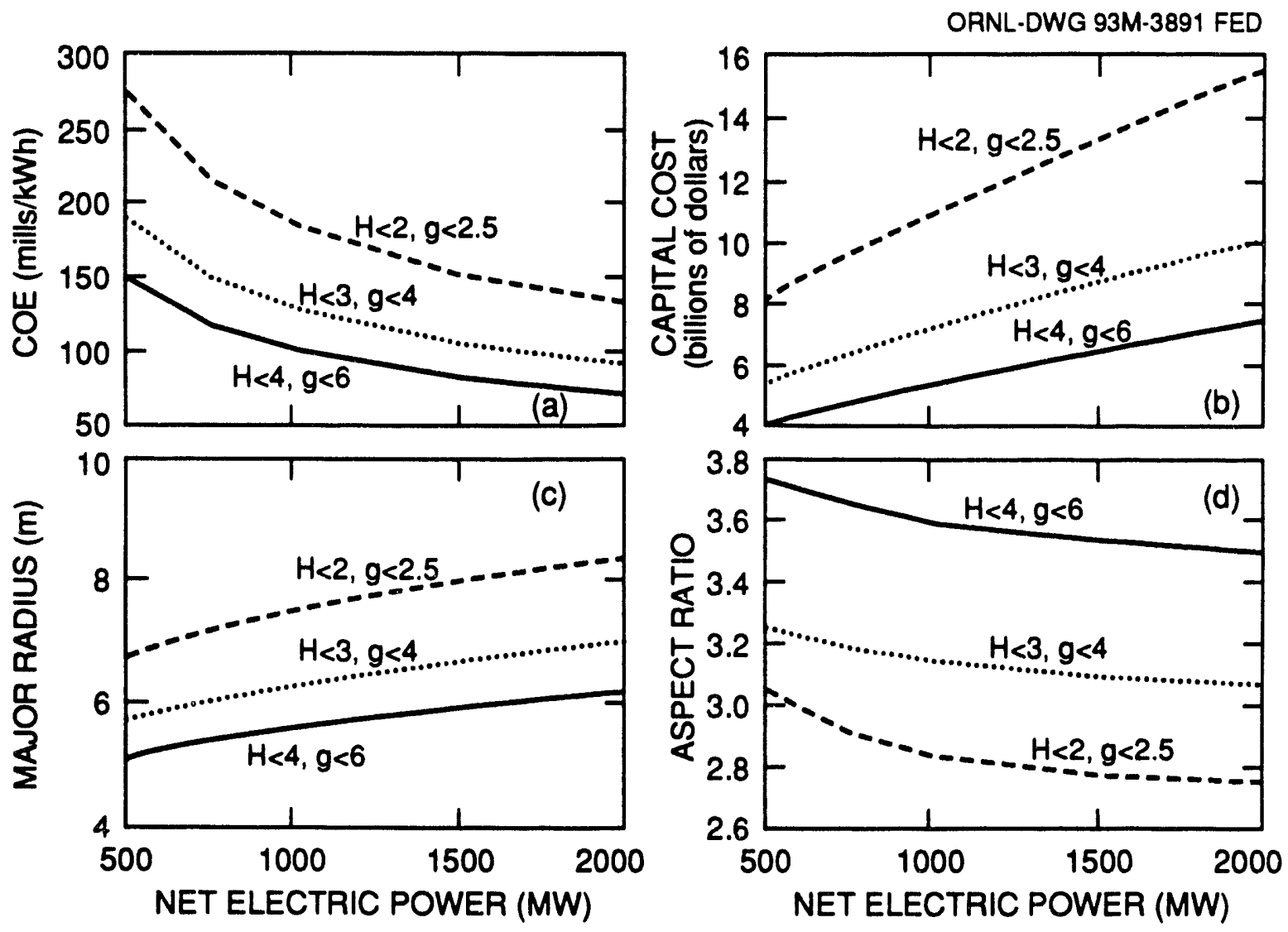

Fig. 4. Minimum COE steady-state reactor parameters vs net electric output. (a) COE (mills/kWh), (b) capital cost $\left(\$ \times 10^{9}\right),(c)$ major radius $(\mathrm{m}),(d)$ aspect ratio. Cases are show for three "physics" levels: (1) present-day $(H \leq 2, g \leq 2.5)$, (2) moderate improved physics $(H \leq 3, g \leq 4)$, and (3) advanced physics $(H \leq 4, g \leq 6)$.

maintain a steady-state plasma current. For the present-day physics case, the energy multiplication $Q$ is always $<10$, the modest physics case has $Q<15$, and to achieve $Q>20$, the advanced physics scenario with high beta must be used. The increase in $Q$ with the more advanced physics scenarios closely follows an increased bootstrap fraction, which is possible under the higher allowable betas.

The higher $Q$ cases have lower plant recirculating power fractions (see Table 5), but even for the $Q=20-25$ cases, the recirculating power fraction is 20 to $25 \%$. Also shown in Table 6 is the fraction of the direct costs related to tokamak specific items. This fraction is high, ranging from 66 to $73 \%$ of the total cost. This is in contrast with predictions for advanced fission concepts, which have a fission core cost fraction of $32 \%$ (Ref. 23). Also shown is the mass power density (MPD), defined as the net electric power-to-mass ratio of the reactor core). We find more variation in the MPD from case to case than for the COE. This is because the reactor core items with significant mass (magnets, shield, structure, etc.) account for only a fraction of the total cost (e.g., only $37 \%$ of the total cost 
Table 6. Minimum COE, steady-state, current-driven reactor parameters

\begin{tabular}{|c|c|c|c|c|c|c|c|c|}
\hline \multirow[b]{2}{*}{ Parameter } & \multicolumn{4}{|c|}{$1000 \mathrm{MW}(\mathrm{e})$} & \multicolumn{2}{|c|}{$500 \mathrm{MW}(\mathrm{e})$} & \multicolumn{2}{|c|}{$2000 \mathrm{MW}(\mathrm{e})$} \\
\hline & $\begin{array}{c}g \leq 4 \\
H \leq 3 \\
995 \geq 3\end{array}$ & $\begin{array}{c}g \leq 6 \\
H \leq 4 \\
995 \geq 3\end{array}$ & $\begin{array}{c}g \leq 4 \\
H \leq 3 \\
995 \geq 5\end{array}$ & $\begin{array}{c}g \leq 6 \\
H \leq 4 \\
995 \geq 5\end{array}$ & $\begin{array}{c}g \leq 4 \\
H \leq 3 \\
995 \geq 3\end{array}$ & $\begin{array}{c}g \leq 6 \\
H \leq 4 \\
q 95 \geq 3\end{array}$ & $\begin{array}{c}g \leq 4 \\
H \leq 3 \\
q 95 \geq 3\end{array}$ & $\begin{array}{c}g \leq 6 \\
H \leqq 4 \\
995 \geq 3\end{array}$ \\
\hline COE, mills/kWh & 130 & 102 & 142 & 106 & 190 & 149 & 93.0 & 72.5 \\
\hline Capital cost, ${ }^{a} \$ \times 10^{9}$ & 7.24 & 5.38 & 8.09 & 5.68 & 5.44 & 4.12 & 10.1 & 7.42 \\
\hline$f_{\text {recirculate, }} \%$ & 33.2 & 24.6 & 31.4 & 21.4 & 38.9 & 29.1 & 28.4 & 20.9 \\
\hline Core mass, ${ }^{b}$ ktonne & 24.5 & 16.0 & 31.9 & 20.1 & 18.8 & 12.5 & 32.4 & 21.5 \\
\hline MPD, ${ }^{c} \mathrm{~kW}(\mathrm{e}) /$ tonne & 40.8 & 62.5 & 31.3 & 49.8 & 26.6 & 40.0 & 61.7 & 93.0 \\
\hline Device core cost, $d \%$ & 71.8 & 65.6 & 73.2 & 66.9 & 71.8 & 66.0 & 71.5 & 64.4 \\
\hline Major radius, m & 6.27 & 5.59 & 6.84 & 5.91 & 5.71 & 5.09 & 6.98 & 6.20 \\
\hline Aspect ratio & 3.14 & 3.59 & 2.87 & 3.30 & 3.25 & 3.73 & 3.07 & 3.50 \\
\hline Plasma current, MA & 19.6 & 12.3 & 16.3 & 10.2 & 15.4 & 9.54 & 24.7 & 15.8 \\
\hline Field on axis, $T$ & 6.17 & 5.86 & 6.16 & 6.04 & 5.96 & 5.60 & 6.43 & 6.17 \\
\hline$B_{\max -T F}$ coil, $T$ & 13.5 & 12.5 & 13.7 & 13.2 & 13.2 & 12.2 & 13.7 & 12.8 \\
\hline $995^{e}$ & 3.0 & 3.0 & 5.0 & 5.0 & 3.0 & 3.0 & 3.0 & 3.0 \\
\hline Injection power, MW & 233 & 122 & 206 & 84.5 & 147 & 74.9 & 373 & 201 \\
\hline B.S. fraction & 0.393 & 0.647 & 0.481 & 0.767 & 0.409 & 0.672 & 0.381 & 0.624 \\
\hline Energy mult. $Q$ & 12.7 & 21.9 & 14.0 & 30.5 & 10.9 & 19.0 & 14.9 & 25.5 \\
\hline Conf. $\boldsymbol{H}$ used & 1.90 & 2.47 & 2.19 & 2.96 & 2.26 & 2.97 & 1.58 & 2.03 \\
\hline Troyon coefficient $\boldsymbol{g}$ used $^{e}$ & 4.0 & 6.0 & 4.0 & 6.0 & 4.0 & 6.0 & 4.0 & 6.0 \\
\hline$<T_{\mathrm{e}}>_{\mathrm{n}}, \mathrm{keV}$ & 22.4 & 19.0 & 17.8 & 15.2 & 22.0 & 18.1 & 22.7 & 19.8 \\
\hline$\left\langle n_{\mathrm{e}}\right\rangle, 10^{20} \mathrm{~m}^{-3}$ & 1.27 & 1.74 & 1.14 & 1.67 & 1.12 & 1.55 & 1.44 & 1.98 \\
\hline Beta, \% & 6.36 & 8.11 & 4.43 & 5.65 & 5.89 & 7.49 & 6.77 & 8.69 \\
\hline Wall load, $\mathrm{MW} / \mathrm{m}^{2}$ & 3.00 & 3.84 & 2.26 & 3.06 & 2.02 & 2.53 & 4.45 & 5.86 \\
\hline
\end{tabular}

a This is the constant dollar capital cost $\left(C_{\mathrm{CO}}\right)$

$b$ Core mass refers to the coils, shield (intemal plus penetration), blanket, first-wall, and divenor.

CMass power density (MPD) = net electric power/core mass.

duTokamak core" costs include everything except buildings, heat transport (although cryogenics are included), turbines, electric plant, beat rejection, and miscellaneous cost categories. In addition to the usual core items (magnets, first wall, shield, blanket, cryostat, etc.), also included as tokamak-specific items are injection power, vacuum systems, tritium processing equipment, plasma fueling, magnet power included as tokamak-specific items are injection power, vacuum systems

eParameter at constraint bound or fixed. 
in the first case of Table 6). In addition to the balance of plant costs (which are fairly constant), much of the cost is in tokamak-related items that have little mass (injection power, tritium and fueling systems, power supplies, cryogenics, vacuum systems, etc.).

\subsubsection{High $q_{95}$ Operation}

Some of the more advanced physics scenarios assumed in the previous section may not be possible unless the edge $q_{95}$ is higher than the nominal lower limit of 3 (in particular, the higher beta levels may require second stability to realize this in practice). The net electric power scans are repeated with the lower limit of $q_{95}$ raised from 3 to 5, and results are shown in Fig. 5(a)-(d) There is only a slight increase in COE (10 to 15\%) for the higher $q_{95}$ cases compared to the lower $q_{95}$ cases in Fig. 4 . These cases have shifted
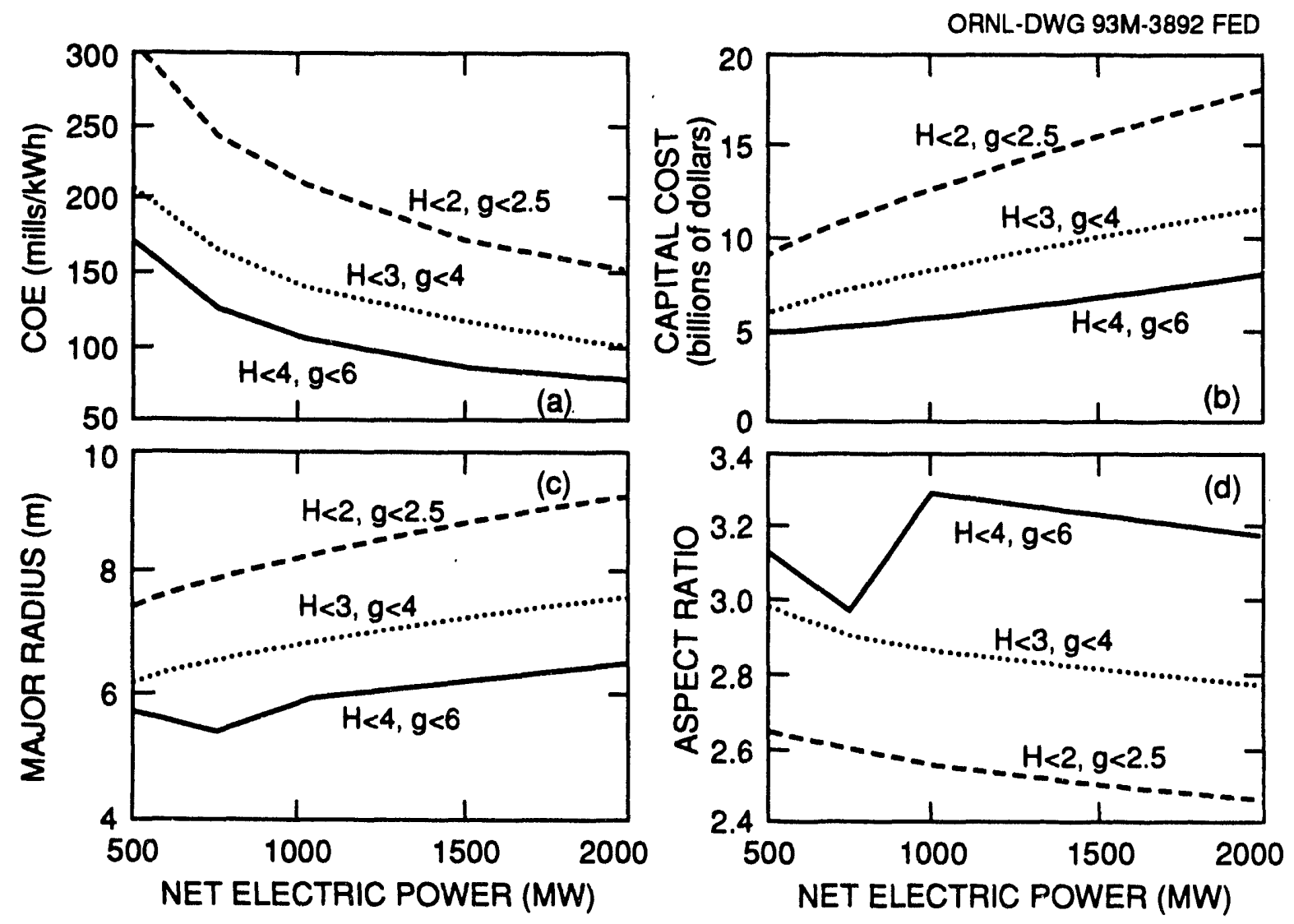

Fig. 5. Minimum COE steady-state reactor parameters vs net electric output with $q_{95} \geq 5$. (a) COE (mills/kWh), (b) capital cost $\left(\$ \times 10^{9}\right)$, (c) major radius (m), and (d) aspect ratio. Cases are show for three "physics" levels: (1) present-day $(H \leq 2, g \leq$ 2.5), (2) moderate improved physics $(H \leq 3, g \leq 4)$, and (3) advanced physics $(H \leq 4$, $g \leq 6)$. 
to slightly lower aspect ratio and larger sizes relative to the lower edge $q_{95}$ cases. Some device parameters from these cases are compared to the $q_{95} \geq 3$ cases in Table 6 . Note that these cases are limited by the upper bound on the Troyon coefficient and not the $H$ factor limit, similar to the behavior observed in the $q_{95} \geq 3$ cases.

\subsection{PULSED REACTORS}

The above cases were steady-state noninductive current-driven cases. The inefficiency of noninductive current drive resulted in large recirculating powers ( $>20 \%$, with plasma energy multiplication $\mathrm{Q}<20$ for $g<6$ for the nominal current drive efficiency). An alternate tokamak reactor approach is to drive the current inductively for a finite pulse length. We investigated this possibility by dropping the noninductive current drive constraint and requiring provision for full inductive plasma current startup and maintenance throughout the entire pulse (see Sect. 2.1.7). This is achieved by allowing the central ohmic heating $(\mathrm{OH})$ solenoid size to increase as needed.

A pulsed reactor would also require some form of energy storage to provide a constant source of electricity to the grid. We ignore any penalty associated with this energy storage mechanism as well as associated load leveling penalties and magnet fatigue issues. In this sense these results should be viewed as being best case. We use $10 \mathrm{~h}$ as the nominal value for the pulse length of the plasma burn, which we suggest may be near the minimum desirable for a practical reactor. This corresponds to roughly $2 \times 10^{4}$ full cycles for the plant lifetime (30 years) and plant availability (75\%) assumed here, which is the level at which fatigue issues begin to be a concern. The sensitivity to the assumed inductive pulse length is addressed. Also, for these cases, we allow additional heating power (which does not contribute to current drive) if it is beneficial in the COE minimization. Otherwise, these cases use the same constraints, variables, and assumptions as the steadystate reactors.

\subsubsection{Pulsed Reactor $(H, g)$ Space}

Figure 6(a) shows the minimum COE contours for 1000-MW(e) reactors in the $(H, g)$ space, produced using the method discussed in Sect. 3.1.1. There is an enlargement of the useful $(H, g)$ space, with the maximum useful $H$ boundary moving up by roughly 0.5 for a constant $g$ level, relative to that in Fig. 1. In this case, energy confinement enhancement $H$ factors of 2 are useful for $g$ values near 2.5. This information is also shown in Fig. 7, which shows the useful $H$ factor vs the maximum allowable $H$ factor for various levels of $g$. The COE magnitude for these cases, at the maximum useful $H$ level, is slightly higher than those of the steady-state reactors for $g$ levels $\leq 4$. While the pulsed reactors are larger and more expensive than the corresponding steady-state cases, they do not require any injection power at the maximum useful $H$ level. This alleviates both the capital cost and recirculating power impacts on the COE. These pulsed reactors tend to have higher aspect ratios (near 5) and have lower plasma currents than the steady-state reactors, both consequences of the inductive pulse length requirement. The pulsed cases also tend to have optimum wall loads 30 to $40 \%$ lower than the corresponding steady- 


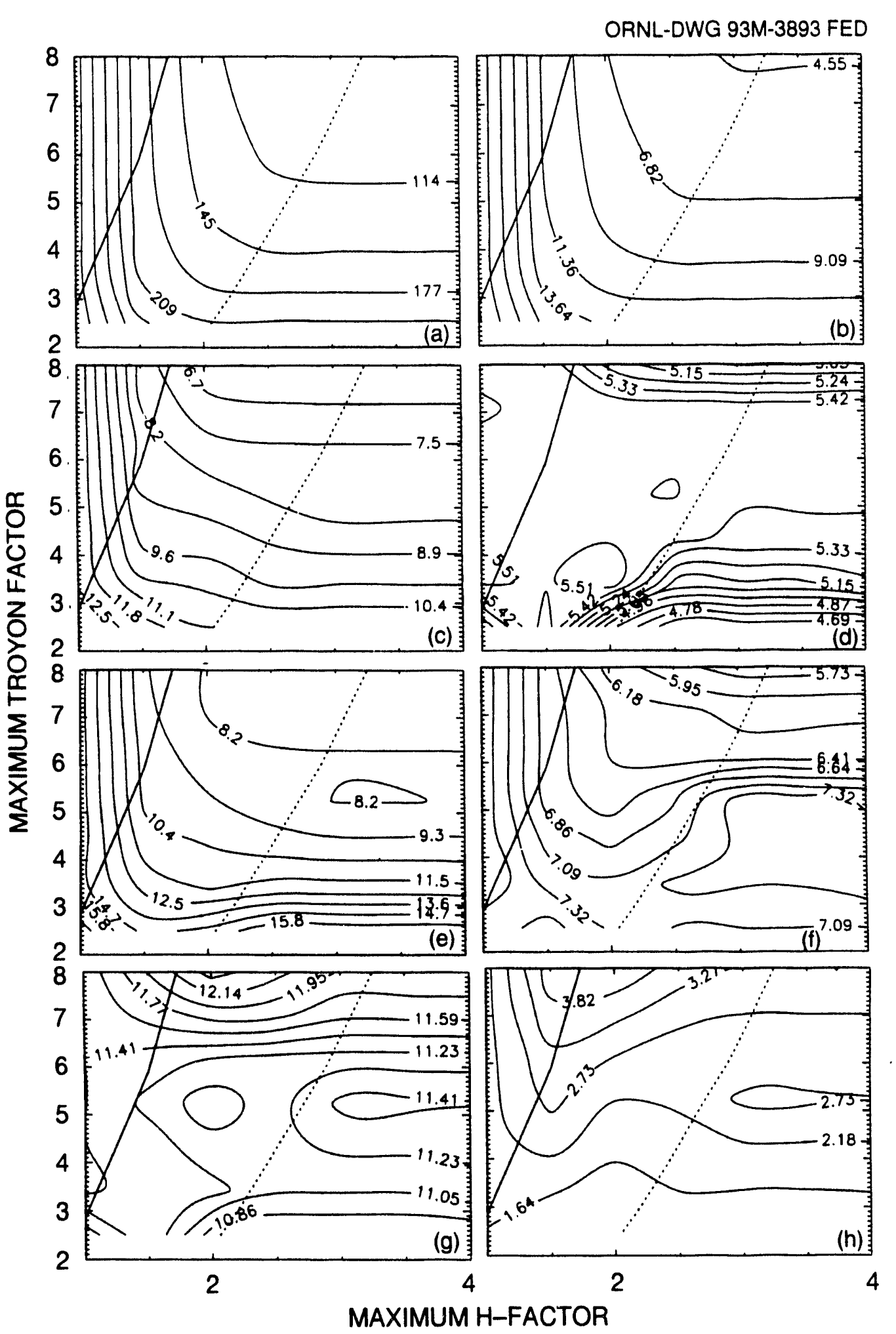

Fig. 6. Minimum COE pulsed reactor parameters in $(H, g)$ space. (a) COE (mills/kWh), (b) capital cost $\left(\$ \times 10^{9}\right),(c)$ major radius $(\mathrm{m}),(d)$ aspect ratio, $(e)$ plasma current (MA), $(f)$ field on axis $(T),(g)$ peak field at the TFC $(T)$, and $(h)$ average neutron wall load $\left(\mathrm{MW} / \mathrm{m}^{2}\right)$. The thick solid line is the maximum useful Troyon $g$ curve, and the dotted line is the maximum useful confinement $H$ factor curve. 


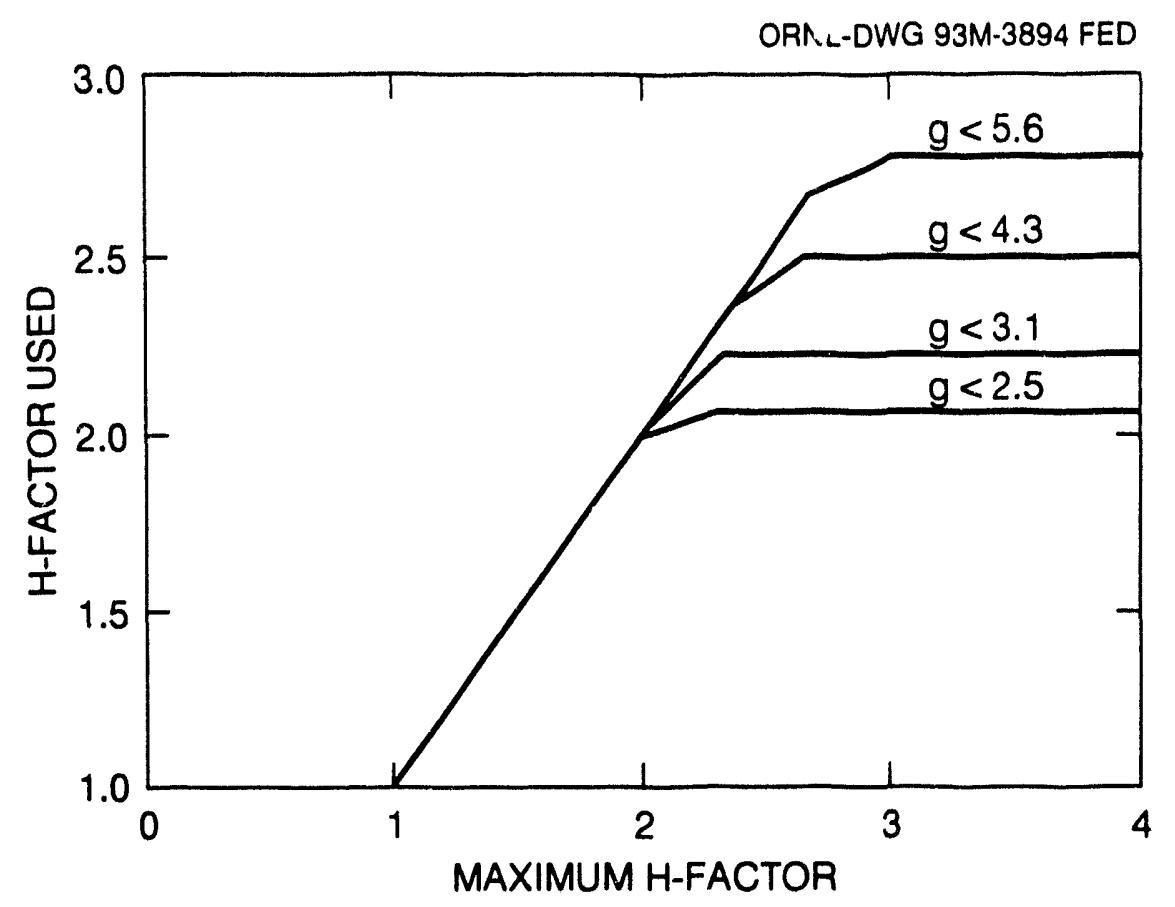

Fig. 7. Variation of useful ITER-89 confinement scaling $H$ factor vs maximum allowed $H$ factor, for various Troyon beta limit coefficients $g$, for pulsed reactor.

state cases described in Sect. 3.1.1. Some of these device parameters are shown in Fig. 6(b)-(h).

\subsubsection{Pulsed Reactor Economy of Scale Sensitivity}

Figure 8(a) shows the minimum COE vs the net electric power for the same beta and confinement limits used in Sect. 3.1.3. Some of the device parameters for these cases are listed in Table 7. The usual COE reduction with increasing power levels is observed, and for the higher plasma performance levels $(H \leq 4, g \leq 6)$, the COE is similar to that of the steady-state case (see Fig. 3) of comparable physics performance. However, these pulsed cases show a stronger COE sensitivity at lower confinement and beta limits. The energy recirculation fractions are 10 to $15 \%$, as set by the balance of plant and pumping power needs. Also, the MPD of these 10-h burn cases is about 50\% lower than the steady-state cases in Table 6, but the differences in the COE are much smaller (3 to 10\%). The capital cost and size of these pulsed cases are larger than the corresponding steadystate cases [compare Fig. 8(b) and $(c)$ and Fig. $4(b)$ and $(c)$ ]. Also, the aspect ratio of these pulsed cases is higher [see Fig. $8(d)$ ] than the steady-state cases to minimize the impact of providing a large $\mathrm{OH}$ transformer.

\subsubsection{Pulsed Reactor Burn Time Sensitivity}

A key factor in the pulsed reactor requirements is the inductively driven pulse length. We used $10 \mathrm{~h}$ as the nominal inductive pulse length for the above cases, but we 


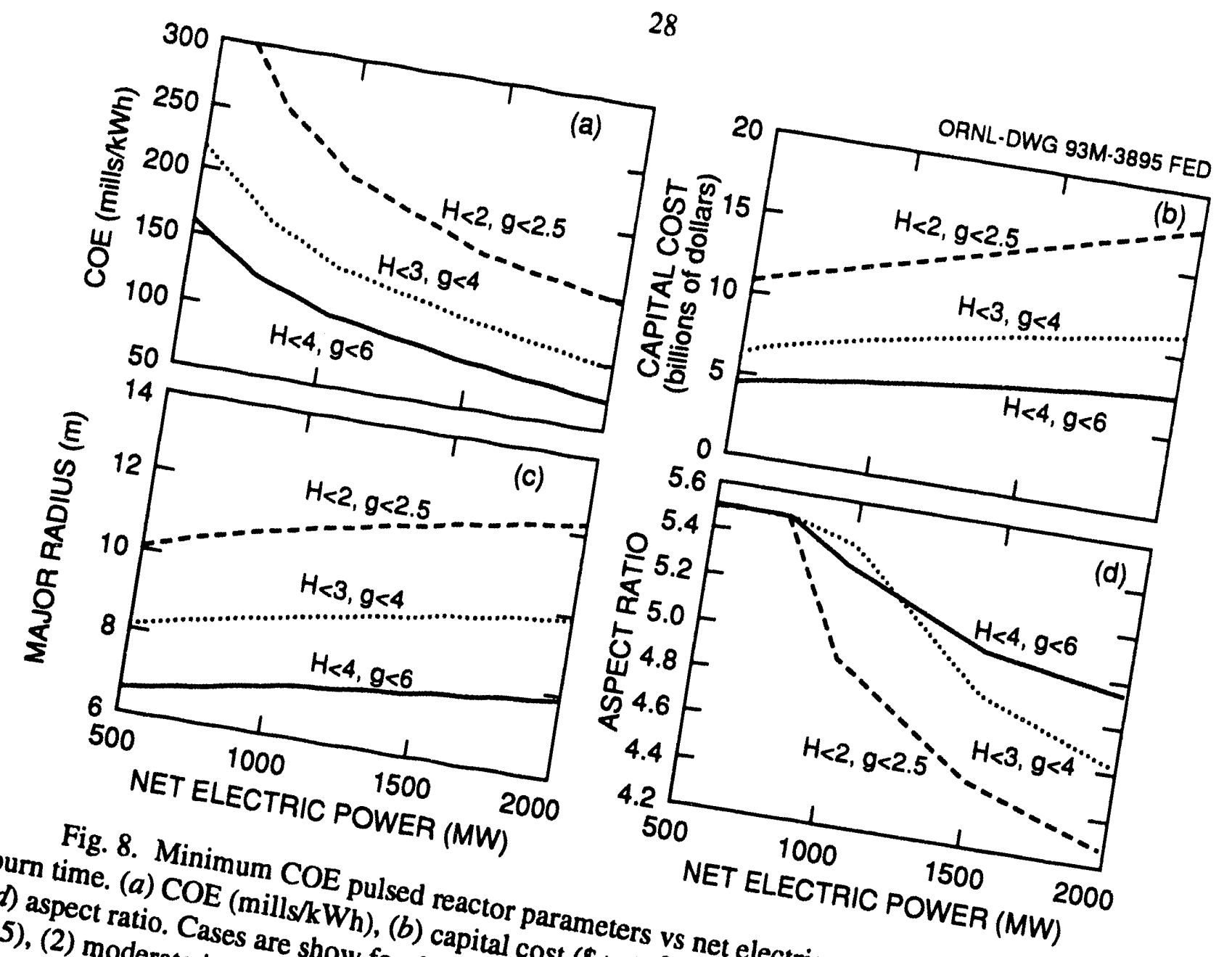

2.5), (2) matio. Cases are show , (b) capital cost (\$ $\times$ rs vs net electric

8 56).

( $1 \leq 3, g \leq 4)$, and (3) advancent-day $(H \leq 2, g \leq$

the same three phy of the results to burn times ran

for a $1000-M W(\mathrm{e})$ power level ased in the net ranging from $10^{3}$ to
tor COE is loctrice

time results are than the corre At the lower end of thic scans above. All s in Fig. 9, for

fatigue issues that realistic, howe

is a strong increase in important, because of our nes [Fig. 4(a)]. The pulsed reac-

be the major driver in the COE at the at low bum times glect of energy stose low burn

for the present-day in the design. This point where ind As the burn time ingerand

to ligate the effect of incre (near 104 strong increase in $\mathrm{COE}$ ) thane requirements inces, there

solenor the neoclassical insed bum time, ther the aggressive occurs at a lowe begin to

increa. Also, the plasm increase in loop the aspect ratio tend physics cases

density-w burn time. Near temperature tends to ind to provide morease [see $F^{5} \mathrm{~s}$ ). To

ratio is at ighted average tem 1000 -s burn times, therease (to lowe more space for the $9(d)$ ]

is at 5.5, and the pla temperature is nes, the aspect ratio iser the loop voltage $\mathrm{OH}$ 
Table 7. Minimum COE, inductively pulsed, extrapolated reactor parameters

\begin{tabular}{|c|c|c|c|c|c|c|c|c|}
\hline \multirow[b]{2}{*}{ Parameter } & \multicolumn{2}{|c|}{$1000 \mathrm{MW}(\mathrm{e})$ at $10 \mathrm{~h}$ for } & \multicolumn{2}{|c|}{$1000 \mathrm{MW}(\mathrm{e})$ at $5 \mathrm{~h}$ for } & \multicolumn{2}{|c|}{$500 \mathrm{MW}(\mathrm{e})$ at $10 \mathrm{~h}$ for } & \multicolumn{2}{|c|}{$2000 \mathrm{MW}(\mathrm{e})$ at $10 \mathrm{~h}$ for } \\
\hline & $\begin{array}{l}g \leq 4 \\
H \leq 3\end{array}$ & $\begin{array}{l}g \leq 6 \\
H \leq 4\end{array}$ & $\begin{array}{l}g \leq 4 \\
H \leq 3\end{array}$ & $\begin{array}{l}g \leq 6 \\
H \leq 4\end{array}$ & $\begin{array}{l}g \leq 4 \\
H \leq 3 \\
\end{array}$ & $\begin{array}{l}g \leq 6 \\
H \leq 4\end{array}$ & $\begin{array}{l}g \leq 4 \\
H \leq 3 \\
\end{array}$ & $\begin{array}{l}g \leq 6 \\
H \leq 4\end{array}$ \\
\hline COE, mills/kWh & 144 & 105 & 126 & 97.5 & 216 & 158 & 99.3 & 73.0 \\
\hline Capital cost, ${ }^{a} \$ \times 10^{9}$ & 8.44 & 5.78 & 7.16 & 5.24 & 6.48 & 4.49 & 11.3 & 7.73 \\
\hline$f_{\text {recirculate, }} \%$ & 12.6 & 12.6 & 12.6 & 12.6 & 15.9 & 15.7 & 10.5 & 10.5 \\
\hline Core mass, ${ }^{b}$ ktonne & 36.3 & 23.6 & 32.8 & 20.0 & 30.4 & 17.6 & 56.1 & 31.6 \\
\hline MPD,c kW(e)/tonne & 27.5 & 42.4 & 30.5 & 50.0 & 15.2 & 28.4 & 35.7 & 63.3 \\
\hline Device core cost, $d \%$ & 75.7 & 68.2 & 72.3 & 65.6 & 75.7 & 69.0 & 74.3 & 66.2 \\
\hline Major radius, m & 8.91 & 7.18 & 8.14 & 6.70 & 8.13 & 6.57 & 9.99 & 8.00 \\
\hline Aspect ratio & 5.41 & 5.31 & 4.42 & 4.65 & 5.50 & 5.50 & 4.63 & 4.85 \\
\hline Plasma current, MA & 9.96 & 7.84 & 12.2 & 8.85 & 7.99 & 6.19 & 15.1 & 10.9 \\
\hline Field on axis, $T$ & 7.48 & 6.92 & 6.45 & 6.25 & 6.97 & 6.56 & 6.94 & 6.79 \\
\hline$B_{\max }-\mathrm{TF}$ coil, $\mathrm{T}$ & 11.3 & 11.2 & 10.7 & 10.9 & 10.7 & 10.8 & 10.8 & 11.0 \\
\hline 995 & $3.0^{e}$ & $3.0^{e}$ & $3.0 e$ & $3.0 e$ & $3.0 e$ & $3.0^{e}$ & 3.02 & $3.0^{e}$ \\
\hline Injection power, $\mathrm{MW}$ & $\mathbf{0}$ & $\mathbf{0}$ & 0 & $\mathbf{0}$ & $\mathbf{0}$ & 0 & $\mathbf{0}$ & $\mathbf{0}$ \\
\hline B.S. fraction & 0.509 & 0.754 & 0.501 & 0.718 & 0.526 & 0.783 & 0.471 & 0.714 \\
\hline Conf. $H$ used & 2.42 & 2.86 & 2.40 & 2.87 & $3.0^{e}$ & 3.57 & 1.97 & 2.32 \\
\hline Troyon coefficient $g$ used & $4.0^{e}$ & $6.0^{e}$ & $4.0^{e}$ & $6.0^{e}$ & $4.0^{\circ}$ & $6.0^{e}$ & $4.0^{e}$ & $6.0^{e}$ \\
\hline$<T_{\mathrm{e}}>_{\mathrm{n}}, \mathrm{keV}$ & 16.3 & 15.9 & 16.5 & 15.4 & 16.1 & 15.8 & 18.1 & 16.7 \\
\hline$\left\langle n_{\mathrm{e}}\right\rangle, 10^{20} \mathrm{~m}^{-3}$ & 1.35 & 1.84 & 1.26 & 1.83 & 1.14 & 1.57 & 1.29 & 1.94 \\
\hline Beta, \% & 3.23 & 5.04 & 3.46 & 5.90 & 3.10 & 4.73 & 4.03 & 5.83 \\
\hline Wall load, MW/m² & 2.02 & 3.03 & 1.99 & 3.04 & 1.27 & 1.90 & 2.72 & 4.38 \\
\hline
\end{tabular}

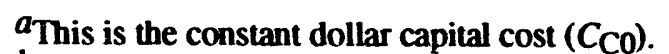

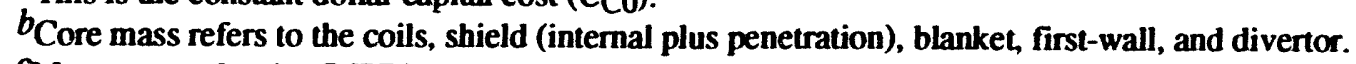

CMass power density (MPD) = net electric power/core mass.

d"Tokamak core" costs include everything except buildings, heat transport (although cryogenics are included), turbines, electric plant, heat rejection. and miscellaneous cost categories. In addition to the usual core items (magnets, first wall, shield, blanket, cryostat, etc.), also included as tokamak-specific items are injection power, vacuum systems, tritium processing equipment, plasma fueling, magnet power supplies, cryogenics, maintenance, and instrumentation and controls.

eParameter at constraint bound or fixed. 

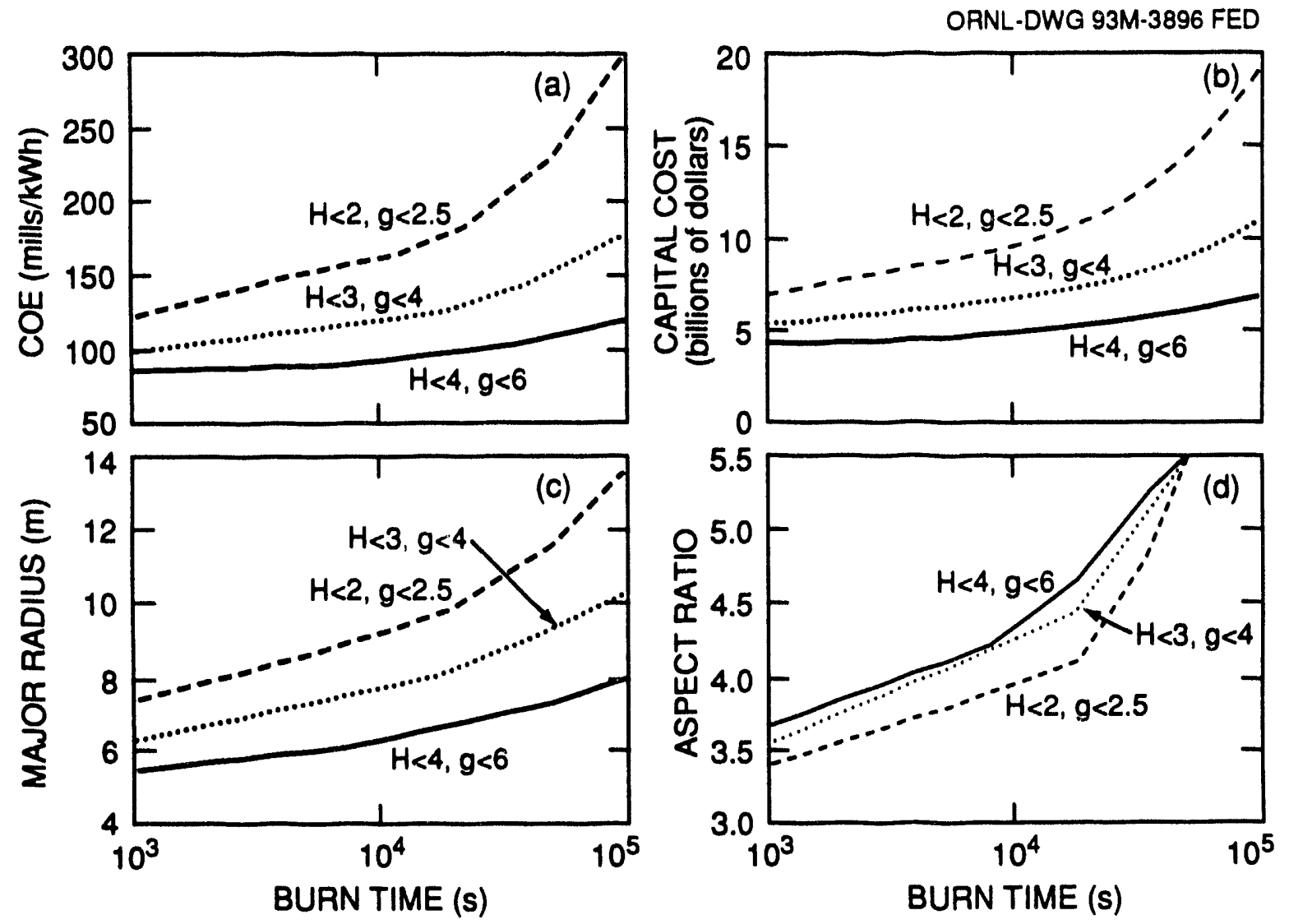

Fig. 9. Minimum COE pulsed reactor parameters vs pulse length for 1000-MW(e) case. (a) COE (mills/kWh), (b) capital cost $\left(\$ \times 10^{9}\right)$, (c) major radius $(\mathrm{m})$, and $(d)$ aspect ratio. Cases are show for three "physics" levels: (1) present-day $(H \leq 2, g \leq 2.5)$, (2) moderate improved physics $(H \leq 3, g \leq 4)$, and (3) advanced physics $(H \leq 4, g \leq 6)$.

The pulsed reactor cases have COEs comparable to their steady-state counterparts (with equivalent physics levels) for burn times near $2 \times 10^{4} \mathrm{~s}$. If lower burn times are feasible without significant penalty, the pulsed reactors become more attractive. This issue will ultimately be resolved by detailed assessments of the energy storage and fatigue issues, which are outside the scope of this work and are being addressed elsewhere. ${ }^{24}$ Some device parameters with reduced burn time requirements are also shown in Table 7.

\subsection{PULSED ITER-LIKE REACTORS}

The presently envisioned ITER-EDA design has a different design approach than that used for the pulsed reactors discussed above. To consider a reactor that could be directly extrapolated from the ITER-EDA design philosophy, we introduce a number of new assumptions here. First, we adopt a single-null plasma with a lower elongation $\left(\kappa_{x}=\right.$ 1.7 vs the nominal 2.0 ). We also require that the aspect ratio be fixed at the relatively low value of 3 and do not allow any additional heating power (all cases must be fully ignited). 


\subsubsection{Pulsed ITER-Like Reactors $(H, g)$ Space}

Figure 10(a) shows the minimum COE for these pulsed ITER EDA-like reactors in $(H, g)$ space. Relative to the previous pulsed reactors, the maximum useful $H$ factor has shifted slightly higher. However, the region between the useful $g$ and useful $H$ curves has dramatically diminished because no auxiliary heating power is allowed. For a similar $g$ level, the COE for these cases is about $10 \%$ higher than the comparable pulsed reactor $\mathrm{COE}$ in Sect. 3.2.1, mainly a consequence of the reduced plasma elongation. Also for these cases, the wall loads tend to be as much as 50 to $60 \%$ lower than those of the pulsed reactors in Sect. 3.2.1. Table 8 lists some device parameters for the advanced and modest physics levels. The useful $H$ factor vs the maximum allowed $H$ factor curves are shown in Fig. 11 (analogous to Fig. 2). The increased range of useful $H$ factors for this class of reactor is evident in Fig. 11, relative to the steady-state cases in Fig. 2.

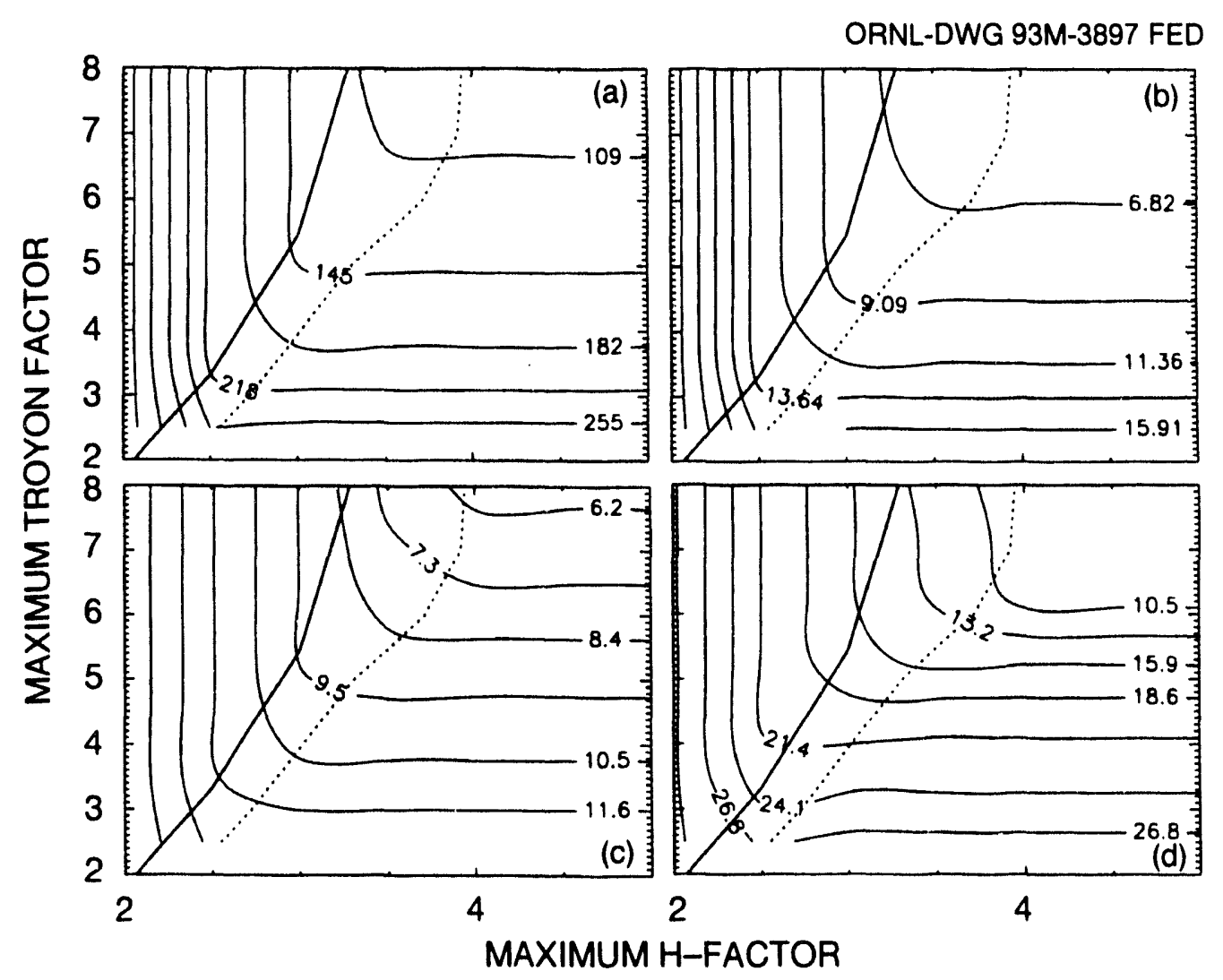

Fig. 10. Minimum COE pulsed reactor parameters in $(H, g)$ space using ITEREDA-like rules. (a) COE (mills/kWh), (b) capital cost $\left(\$ \times 10^{9}\right),(c)$ major radius $(\mathrm{m})$, and (d) plasma current (MA). 
Table 8. Minimum COE, pulsed, ITER-like extrapolated reactor parameters (aspect ratio fixed at 3 , and no injection power allowed)

\begin{tabular}{|c|c|c|c|c|c|c|c|c|}
\hline \multirow[b]{2}{*}{ Parameter } & \multicolumn{2}{|c|}{$1000 \mathrm{MW}(\mathrm{e})$ at $10 \mathrm{~h}$ for } & \multicolumn{2}{|c|}{$1000 \mathrm{MW}(\mathrm{e})$ at $5 \mathrm{~h}$ for } & \multicolumn{2}{|c|}{$\underline{500 \mathrm{MW}(\mathrm{e}) \text { at } 10 \mathrm{~h} \text { for }}$} & \multicolumn{2}{|c|}{$2000 \mathrm{MW}(\mathrm{e})$ at $10 \mathrm{~h}$ for } \\
\hline & $\begin{array}{l}g \leq 4 \\
H \leq 3\end{array}$ & $\begin{array}{l}g \leq 6 \\
H \leq 4\end{array}$ & $\begin{array}{l}g \leq 4 \\
H \leq 3\end{array}$ & $\begin{array}{l}g \leq 6 \\
H \leq 4\end{array}$ & $\begin{array}{c}g \leq 4 \\
H \leq 3^{f}\end{array}$ & $\begin{array}{l}g \leq 6 \\
H \leq 4\end{array}$ & $\begin{array}{l}g \leq 4 \\
H \leq 3 \\
\end{array}$ & $\begin{array}{l}g \leq 6 \\
H \leq 4\end{array}$ \\
\hline COE, mills/kWh & 171 & 121 & 141 & 108 & & 196 & 116 & 83.5 \\
\hline Capital cost, $a \$ \times 10^{9}$ & 10.1 & 6.76 & 8.05 & 5.85 & & 5.62 & 13.4 & 8.98 \\
\hline$f_{\text {recirculate, }} \%$ & 12.6 & 12.6 & 12.6 & 12.6 & & 15.7 & 10.5 & 10.5 \\
\hline Core mass, $b$ ktonne & 50.6 & 31.9 & 39.4 & 25.1 & & 24.3 & 67.6 & 41.0 \\
\hline MPD, $c$ kW(e)/tonne & 19.8 & 31.3 & 25.4 & 39.8 & & 20.6 & 29.6 & 48.8 \\
\hline Device core cost, $d \%$ & 75.7 & 69.4 & 72.4 & 66.3 & & 70.2 & 75.0 & 67.8 \\
\hline Major radius, m & 10.2 & 7.88 & 9.09 & 7.53 & & 8.05 & 11.3 & 9.04 \\
\hline Aspect ratio & 3 & 3 & 3 & 3 & & 3 & 3 & 3 \\
\hline Plasma current, MA & 21.5 & 11.0 & 19.2 & 14.4 & & 13.4 & 24.9 & 16.3 \\
\hline Field on axis, $T$ & 4.83 & 5.42 & 4.87 & 4.53 & & 3.68 & 5.07 & 5.11 \\
\hline$B_{\max -T F}$ coil, $T$ & 8.99 & 11.0 & 9.38 & 9.34 & & 7.31 & 9.28 & 9.96 \\
\hline$q_{95}$ & $3.0^{e}$ & 5.40 & $3.0^{e}$ & 3.27 & & 3.05 & $3.0^{e}$ & 3.93 \\
\hline B.S. fraction & 0.388 & 0.763 & 0.389 & 0.610 & & 0.598 & 0.385 & 0.651 \\
\hline Conf. $H$ used & $3.0^{e}$ & 3.69 & 2.67 & 3.15 & & $4.0^{e}$ & 2.29 & 2.75 \\
\hline Troyon coefficient $g$ used & $4.0^{e}$ & $6.0 e$ & $4.0^{e}$ & $6.0^{e}$ & & $6.0^{e}$ & $4.0^{e}$ & $6.0^{e}$ \\
\hline$<T_{\mathrm{e}}>_{\mathrm{n}}, \mathrm{keV}$ & 25.9 & 17.0 & 20.6 & 19.2 & & 21.6 & 23.1 & 19.3 \\
\hline$\left\langle n_{\mathrm{e}}\right\rangle, 10^{20} \mathrm{~m}^{-3}$ & 0.553 & 0.977 & 0.719 & 0.972 & & 0.612 & 0.686 & 1.03 \\
\hline Beta, $\%$ & 5.21 & 4.65 & 5.21 & 7.59 & & 8.14 & 5.21 & 6.36 \\
\hline Wall load, $\mathrm{MW} / \mathrm{m}^{2}$ & 0.967 & 1.61 & 1.22 & 1.76 & & 0.801 & 1.55 & 2.41 \\
\hline
\end{tabular}

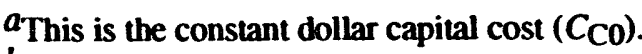

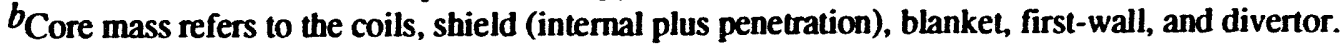

cMass power density (MPD) = net electric power/core mass.

d"Tokamak core" costs include everything except buildings, heat transport (although cryogenics are included), turbines, electric plant, heat rejection, and miscellaneous cost categories. In addition to the usual core items (magnets, first wall, shield, blanket, cryostat, etc.), also included as tokamak-specific items are injection power, vacuum systems, tritium processing equipment, plasma fueling, magnet power supplies, cryogenics, maintenance, and instrumentation and controls.

eParameter at constraint bound or fixed.

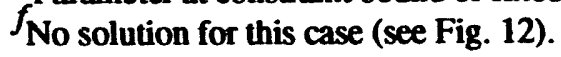




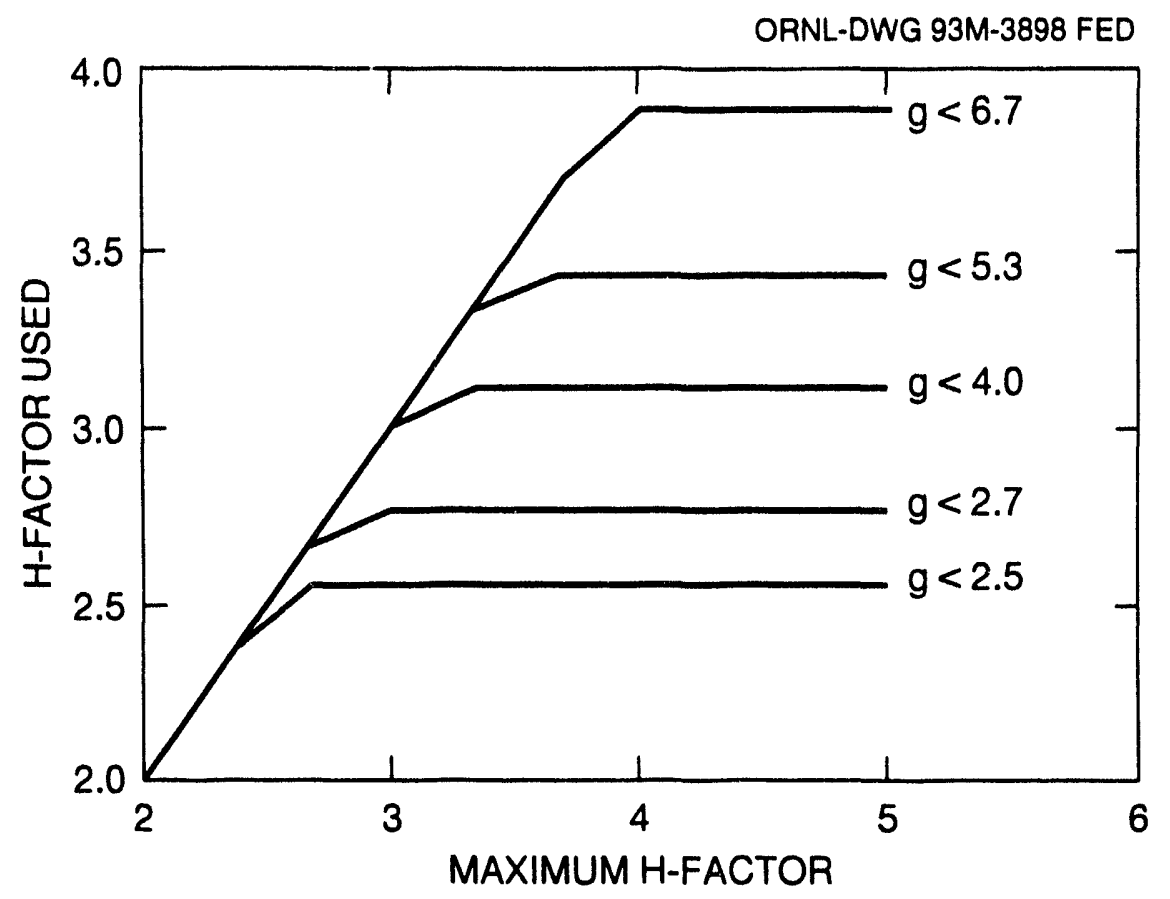

Fig. 11. Variation of useful ITER-89 confinement scaling $H$ factor vs maximum allowed $H$ factor, for various Troyon beta limit coefficients $g$, for ITER-like pulsed reactors.

\subsubsection{Pulsed ITER-Like Reactors, Economy of Scale}

The ITER-like pulsed reactors are more sensitive to reduced power levels than the previous cases, especially at the present-day physics levels (see Fig. 12). This is because there is no auxiliary heating power available, and attaining ignition at lower net electric power levels is problematic (i.e., even though the required power level drops, the size must increase to maintain power balance, forcing the plasma conditions to a low-power density). This results in the unusual occurrence of increasing capital costs with decreasing net electric power, highlighting the difficulty of using ignited tokamaks as a path toward small-sized demonstration power reactors. However, for the advanced physics assumptions, this situation is alleviated. Table 8 lists some parameters of selected 500- and 2000-MW(e) level cases.

\subsubsection{Pulsed ITER-Like Reactors, Burn Time Sensitivity}

Figure 13 shows the sensitivity of these pulsed reactors to the required burn time. Relative to the previous pulsed reactors (see Fig. 7), the knee in the curve occurs at roughly half the burn time for a given physics level. In this case, for the present-day physics level, the COE increases rapidly above burn times of $10^{4} \mathrm{~s}$. Much of the increased sensitivity to burn time for these pulsed reactors is related to the fixed-aspect ratio assumption. As shown in Sect. 3.2.3, if permitted, the aspect ratio tends to increase 

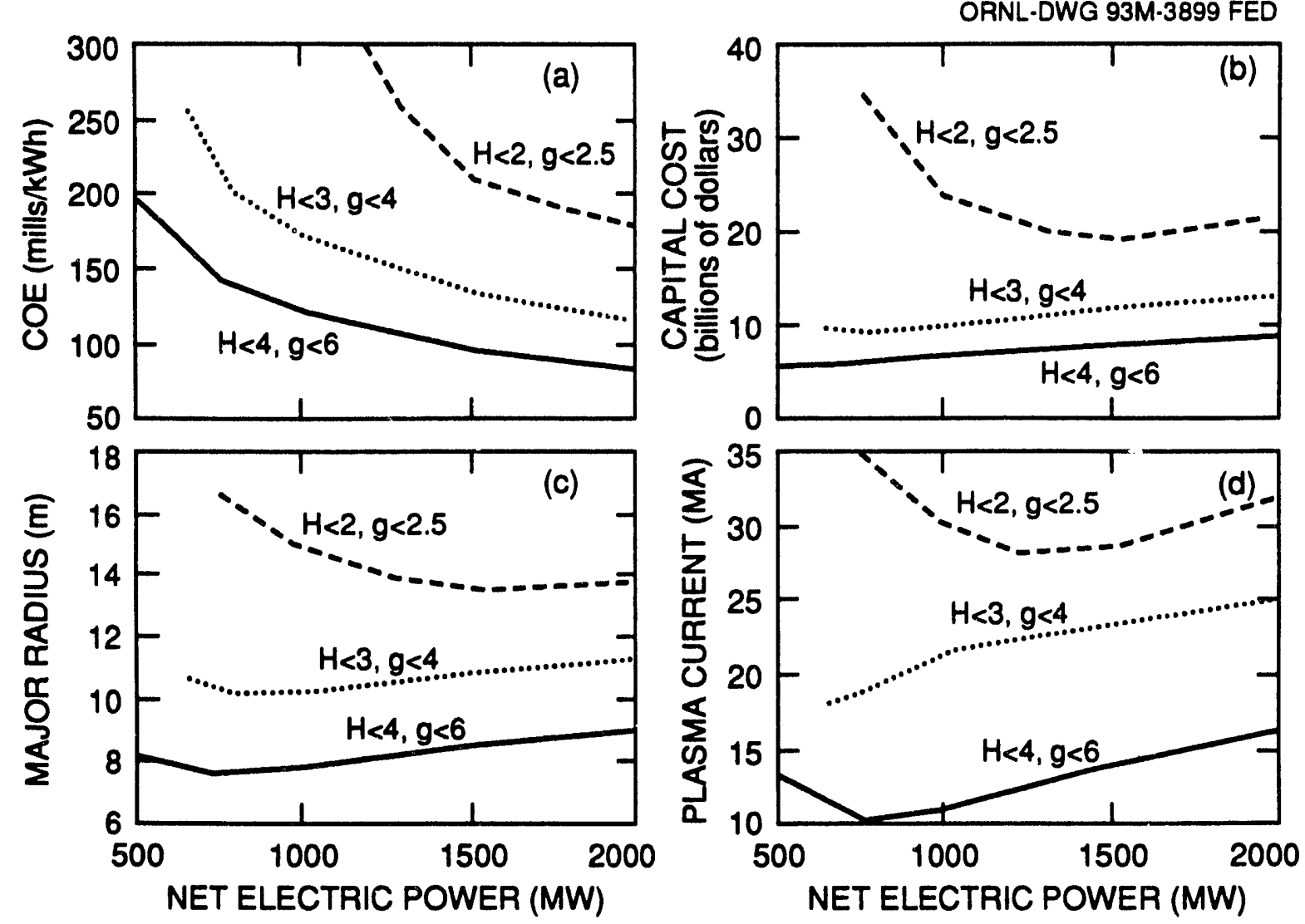

Fig. 12. Minimum COE pulsed reactor parameters vs net electric output with 10-h burn time using ITER-EDA-like rules. (a) COE (mills/kWh), (b) capital cost $\left(\$ \times 10^{9}\right)$, (c) major radius (m), and (d) plasma current (MA). Cases are show for three "physics" levels: (1) present-day $(H \leq 2, g \leq 2.5)$, (2) moderate improved physics $(H \leq 3, g \leq 4)$, and (3) advanced physics $(H \leq 4, g \leq 6)$.

with increasing burn time to provide more room for the ever-increasing $\mathrm{OH}$ solenoid size requirements and to reduce the neoclassical increases in loop voltage.

\subsection{REACTORS WITH NO $H$ OR $g$ LIMITS}

In this section we address the reactor implications for cases that are not constrained by the usual tokamak limits. Although the following devices are not, of course, physically realizable under today's knowledge base, they should be considered as ultimate limits that a fusion reactor could approach in terms of advanced physics, but at the same engineering allowables as the previous cases. All examples here are steady state, and nominal current drive efficiency and $q_{95} \geq 3$ are used. Some device parameters from selected cases are shown in Table 9 along with the nominal steady-state reactor values in column 1 for comparison. 


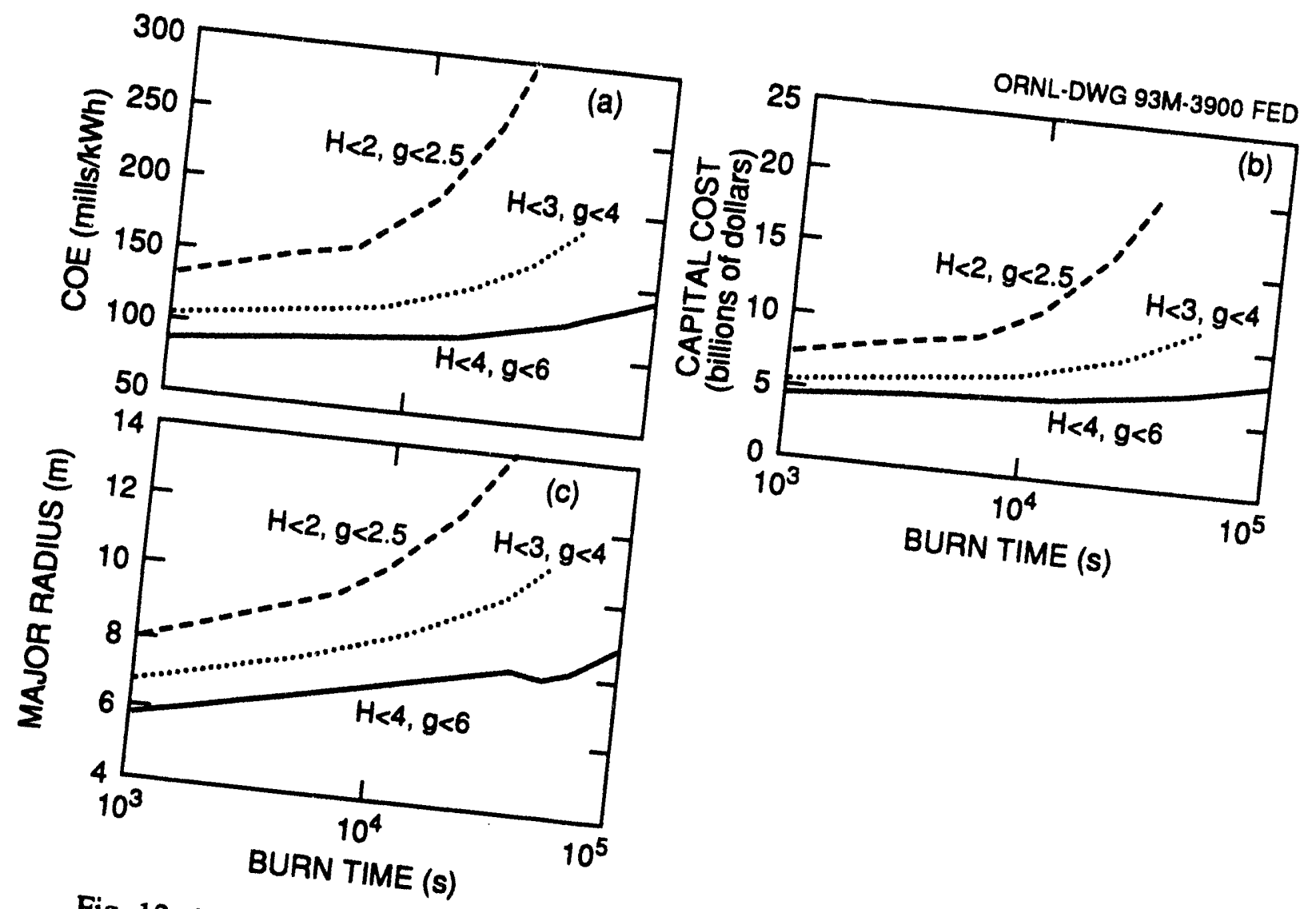

Fig. 13. Minimum $C O E_{\text {pulse }}$

case using ITER-EDA-like rules. (a) reactor parameters vs pulse length for $1000-M W(c)$ $g \leq 2.5)$, (2) modm). Cases are show for (mills/kWh), (b) capital cost $\left(\$ \times 10^{9}\right)$.MW (e) $8 \leq 6$ ).

Troyon beta limit or ITER-P is that of a tokamak with no limit on $g$ or $H$-that is, no plasma current to of the inclusion of the scaling restriction. There is still a confinement the more stringent of the the alphas (see Sect. 2.1). The neocland also a limit on the minimum COE vs electric outpunsiderations for these Ultimate result in 20 to 25\% lower COEs th shown as the solid curve in Fig cases. The resulting reactors in Sect. 3.1.3. Cost and size the best physics scenario sho. 14(a). These cases physics case aspect ratio ranges between 3 andar declines relative to the the standard near $15 \%$, which in Sect. 3.1.3 [see Fig. 14 3 and similar to the most aggres in Sect. 
Table 9. Neoclassical confinement reactor parameters

\begin{tabular}{|c|c|c|c|}
\hline \multirow{3}{*}{ Parameter } & \multicolumn{3}{|c|}{ Power level [MW(e)] at } \\
\hline & \multirow{2}{*}{$\begin{array}{c}\begin{array}{c}\text { Nominal steady } \\
\text { state }\end{array} \\
1000\end{array}$} & \multicolumn{2}{|c|}{$\begin{array}{c}\text { Neoclassical } \\
\text { tokamak }\end{array}$} \\
\hline & & 500 & 1000 \\
\hline COE, mills/kWh & 130 & 111 & 72.4 \\
\hline Capital cost, $a \$ \times 10^{9}$ & 7.24 & 2.85 & 3.44 \\
\hline$f_{\text {recirculate, }} \%$ & 33.2 & 15.7 & 12.6 \\
\hline Core mass, ${ }^{b}$ ktonne & 24.5 & 7.31 & 8.5 \\
\hline MPD,c kW(e)/tonne & 40.8 & 68.4 & 118 \\
\hline Device core cost, $d \%$ & 71.8 & 57.3 & 53.0 \\
\hline Major radius, m & 6.27 & 4.03 & 4.23 \\
\hline Aspect ratio & 3.14 & 3.49 & 3.60 \\
\hline Plasma current, MA & 19.6 & 6.96 & 7.95 \\
\hline Field on axis, $T$ & 6.17 & 4.03 & 4.53 \\
\hline$B_{\max -\mathrm{TF}}$ coil, $\mathrm{T}$ & 13.5 & 11.1 & 11.9 \\
\hline 995 & $3.0^{e}$ & $3.0^{e}$ & $3.0^{e}$ \\
\hline Injection power, MW & 233 & 0 & 0 \\
\hline B.S. fraction & 0.393 & 1.00 & 1.00 \\
\hline \multicolumn{4}{|l|}{ Conf. $H$ used } \\
\hline \multicolumn{4}{|c|}{ Troyon coefficient $g$ used } \\
\hline$<T_{\mathrm{e}}>_{\mathrm{n}}, \mathrm{keV}$ & 22.4 & 7.93 & 7.59 \\
\hline$\left\langle n_{\mathrm{e}}\right\rangle, 10^{20} \mathrm{~m}^{-3}$ & 1.27 & 3.87 & 5.43 \\
\hline Beta, \% & 6.36 & 14.4 & 15.3 \\
\hline Wall load, $\mathrm{MW} / \mathrm{m}^{2}$ & 3.00 & 3.20 & 5.81 \\
\hline
\end{tabular}

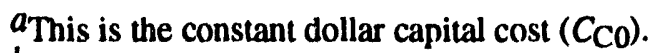

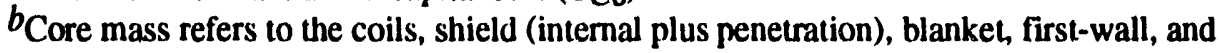
divertor.

$c_{\text {Mass power density }(M P D)}=$ net electric power/core mass.

d"Tokamak core" costs include everything except buildings, heat transport (although cryogenics are included), turbines, electric plant, heat rejection, and miscellaneous cost categories. In addition to the usual core items (magnets, first wall, shield, blanket, cryostat, etc.), also included as tokamak-specific items are injection power, vacuum systems, tritium processing equipment, plasma fueling, magnet power supplies, cryogenics, maintenance, and instrumentation and controls.

$e_{\text {Parameter at constraint bound or fixed. }}$ 


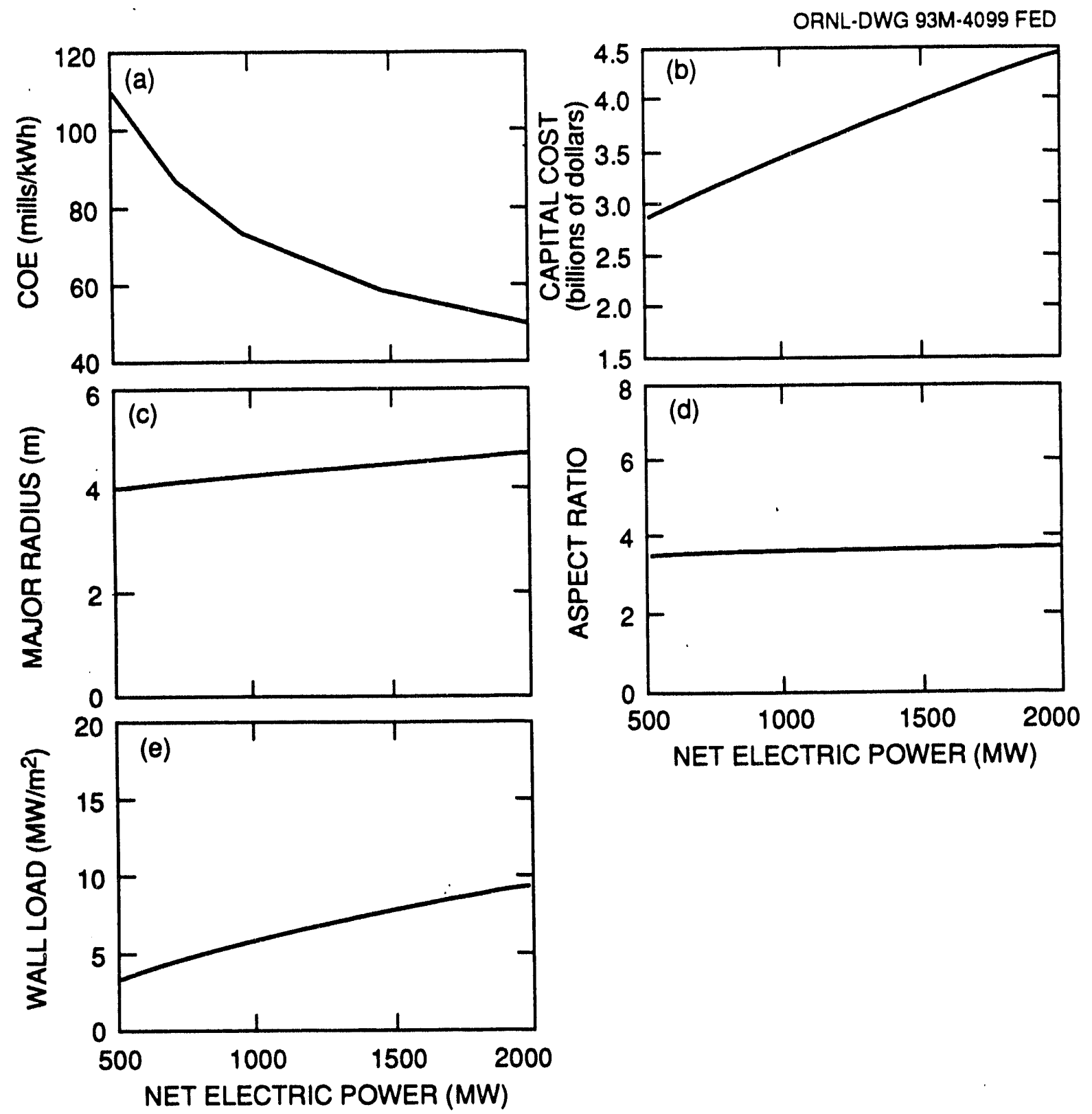

Fig. 14. Minimum COE steady-state reactor parameters with no $H$ factor or $\boldsymbol{g}$ limits vs net electric output. (a) COE (mills $/ \mathrm{kWh}$ ), (b) capital cost $\left(\$ \times 10^{9}\right),(c)$ major radius $(\mathrm{m}),(d)$ aspect ratio, and $(e)$ average neutron wall load $\left(\mathrm{MW} / \mathrm{m}^{2}\right)$. Only neoclassical confinement is used. 


\section{SUMMARY}

The impact on commercial tokamak embodiments from improvements in plasma confinement and beta has been systematically investigated. This study is done with a tokamak systems optimization code that couples physics with engineering/costing models. Cases were investigated for steady-state reactors, pulsed reactors, and ITERextrapolated pulsed reactors (which used somewhat more conservative plasma configuration assumptions than the nominal pulsed reactors). The COE and device costs for these cases are summarized in Table 10. It is seen that attainment of advanced physics levels, relative to the nominal present-day physics levels, offers reductions in the plant COE and capital cost of approximately a factor of 2 for a constant unit size (measured by electric power level) or a reduction of a factor of 4 in the unit size for a constant COE. By advanced physics, we mean attainment of high beta levels (corresponding to Troyon beta coefficients $g$ of 6 ) and good plasma confinement (attainment of ITER-89 L-mode scaling $H$ factor enhancements of 2.5 to 3.0). Some additional key results from this study are summarized below.

- A surprisingly narrow range of plasma confinement and beta are found to be useful in minimizing the COE for a tokamak reactor. Improvements in only one of these quantities is not useful beyond some point, without accompanying improvements in the other.

- For the plasma beta limited by a Troyon coefficient ( $g$ ) near 4.3 (\% mT/MA), confinement levels characterized by $H$ factor enhancements (where $\tau_{E}=H^{*} \tau_{E L}$, and where $\tau_{E L}$ is the confinement time predicted by the ITER-89 L-mode scaling) of only 2 are useful for our nominal steady-state driven tokamak. These confinement levels are similar to those observed in present-day experiments. If the permissible Troyon beta coefficient is near 6, the useful $H$ factor confinement range increases to 2.5 , still close to present-day confinement levels. If the reactor embodiment is forced to use a higher confinement $H$ factor than optimum for a given Troyon beta coefficient, then the design will move to a less optimum point with a correspondingly higher cost-ofelectricity.

- Increases in current drive efficiency reduce the COE by lowering the power recirculating fraction but do not significantly alter the useful range of confinement and beta.

- Operation at a high-edge safety factor $q_{95}$ (e.g., for second stability) results in a minimal increase on the COE.

- Inductively driven pulsed reactors have somewhat increased useful ranges of confinement, relative to the steady-state cases. For a Troyon beta limit coefficient $g$ near 4.3, $H$ factors up to 2.5 are useful, and for $g$ near $6, H$ factors up to 3 are useful.

- The inductively driven pulsed reactor performance is sensitive to the required pulse length. With comparable $H$ factor and $g$ levels, pulsed reactors obtain COEs comparable to steady-state cases if burn times near $5 \mathrm{~h}$ can be attained without significant penalty for energy storage and fatigue issues. Higher burn times tend to have a severe detrimental impact on the pulsed cases due to the volt-second requirements.

- The pulsed reactors tend towards high aspect ratio (4-5) to minimize the impact of supplying a large ohmic heating coil, whereas the steady-state reactors optimize in the range of $A \sim 3-4$. 
Table 10. Summary of the pulsed and steady-state reactor cases ${ }^{a}$

\begin{tabular}{|c|c|c|c|c|c|c|c|c|c|}
\hline & \multicolumn{3}{|c|}{$500 \mathrm{MW}(\mathrm{e})$} & \multicolumn{3}{|c|}{$1000 \mathrm{MW}(\mathrm{e})$} & \multicolumn{3}{|c|}{$2000 \mathrm{MW}(\mathrm{e})$} \\
\hline & $\begin{array}{l}\text { Nominal } \\
\text { physics }\end{array}$ & $\begin{array}{c}\text { Intermediate } \\
\text { physics }\end{array}$ & $\begin{array}{l}\text { Advanced } \\
\text { physics }\end{array}$ & $\begin{array}{l}\text { Nominal } \\
\text { physics }\end{array}$ & $\begin{array}{c}\text { Intermediate } \\
\text { physics }\end{array}$ & $\begin{array}{l}\text { Advanced } \\
\text { physics }\end{array}$ & $\begin{array}{l}\text { Nominal } \\
\text { physics }\end{array}$ & $\begin{array}{c}\text { Intermediate } \\
\text { physics }\end{array}$ & $\begin{array}{l}\text { Advanced } \\
\text { physics }\end{array}$ \\
\hline & \multicolumn{9}{|c|}{ Pulsed, ITER-extrapolated reactor } \\
\hline $\begin{array}{l}\text { COE, mills } / \mathrm{kWh} \\
\text { Capital cost, } \$ \times 10^{9}\end{array}$ & $\begin{array}{l}\text { No soln } \\
\text { No soln }\end{array}$ & $\begin{array}{l}>300 \\
10\end{array}$ & $\begin{array}{l}196 \\
5.6\end{array}$ & $\begin{array}{l}>300 \\
\sim 20\end{array}$ & $\begin{array}{l}171 \\
10\end{array}$ & $\begin{array}{l}121 \\
6.8\end{array}$ & $\begin{array}{l}179 \\
22\end{array}$ & $\begin{array}{l}116 \\
13\end{array}$ & $\begin{array}{l}84 \\
9.0\end{array}$ \\
\hline & \multicolumn{9}{|c|}{ Pulsed reactor } \\
\hline $\begin{array}{l}\text { COE, mills } / k W h \\
\text { Capital cost, } \$ \times 10^{9}\end{array}$ & $\begin{array}{l}>300 \\
11\end{array}$ & $\begin{array}{l}216 \\
6.5\end{array}$ & $\begin{array}{l}158 \\
4.5\end{array}$ & $\begin{array}{l}212 \\
13\end{array}$ & $\begin{array}{l}144 \\
8.4\end{array}$ & $\begin{array}{l}105 \\
5.8\end{array}$ & $\begin{array}{l}147 \\
18\end{array}$ & $\begin{array}{l}99 \\
11\end{array}$ & $\begin{array}{l}73 \\
7.7\end{array}$ \\
\hline & \multicolumn{9}{|c|}{ State-state reactor $(q \geq 3)$} \\
\hline $\begin{array}{l}\text { COE, mills } / \mathrm{kWh} \\
\text { Capital cost, } \$ \times 10^{9}\end{array}$ & $\begin{array}{l}272 \\
8.3\end{array}$ & $\begin{array}{l}190 \\
5.4\end{array}$ & $\begin{array}{l}149 \\
4.1\end{array}$ & $\begin{array}{l}187 \\
11\end{array}$ & $\begin{array}{l}130 \\
7.2\end{array}$ & $\begin{array}{l}102 \\
5.4 \\
\end{array}$ & $\begin{array}{l}133 \\
15 \\
\end{array}$ & $\begin{array}{l}93.0 \\
10\end{array}$ & $\begin{array}{l}72.5 \\
7.4\end{array}$ \\
\hline
\end{tabular}

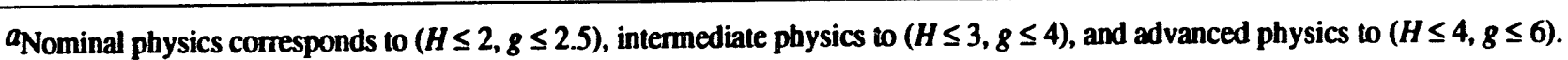


- All reactor types are sensitive to the improvements in physics, in particular the attainable Troyon beta limit factor $g$. For example, operation with advanced physics $(H \leq 4$, $g<6)$ compared to the present-day physics $(H \leq 2, g \leq 2.5)$ offers (1) about a factor of 2 reduction in the COE for constant unit plant size or (2) up to a reduction in 4 in the plant unit size (and cost) for the same COE. 


\section{REFERENCES}

1. "TPX-Tokamak Physics Experiment," Conceptual Design Overview, PPPL Report 91-930323-PPPL/WREIERSEN-01, presented at the TPX conceptual design review March 29, 1993.

2. "The ITER Project, Preliminary Design Outline for the Second Technical Advisory Committee," ITER-TAC-2-01, presented by the ITER Director, March 1993.

3. S. W. Haney et al., "A SUPERCODE for Systems Analysis of Tokamak Experiments and Reactors," Fusion Technology 21, 1749 (1992).

4. J. Sheffield et al., "Cost Assessment of a Generic Magnetic Fusion Reactor," Fusion Technology 9, 199 (1986).

5. F. Najmabadi et al., The ARIES-I Tokamak Reactor Study, UCLA-PPG-1323, 1991.

6. W. M. Stacey et al., Tokamak Experimental Power Reactor Studies, ANL/CTR-75-2, Argonne National Laboratory, 1975.

7. D. A. Ehst, K. Evans, Jr., and W. M. Stacey, "The Influence of Physics Parameters on Tokamak Reactor Design," Nucl. Technol. 43, 28 (1979).

8. P. I. Cooke, R. Hancox, and W. R. Spears, Parameters of a Reference Tokamak Reactor, CLM-R298, AEA Culham Laboratory, December 1989.

9. C. Baker, Starfire-A Commercial Tokamak Fusion Power Plant Study, ANL/FPP80-1, Argonne National Laboratory, 1980.

10. N. A. Uckan, ITER-Physics Design Guidelines, ITER Document Series, No. 10, IAEA, Vienna, 1990.

11. P. N. Yushmanov et al., "Scalings for Tokamak Energy Confinement," Nucl. Fusion 30, 1999 (1990).

12. N. A. Uckan and J. Sheffield, A Simple Procedure for Establishing Ignition Conditions in Tokamaks, OFNL/TM-9722, Martin Marietta Energy System, Inc., Oak Ridge Natl. Lab., 1985.

13. S. P. Hirshman and D. J. Sigmar, "Neoclassical Transport of Impurities in Tokamak Plasma," Nucl. Fusion 21, 1079 (1981).

14. F. Troyon et al., "MHD Limits to Plasma Confinement," Plasma Phys. Controlled Fusion 26, 209 (1984).

15. S. P. Hirshman, Phys. Fluids 31, 3150 (1988).

16. N. A.Uckan, Oak Ridge National Laboratory, private communication, February 1991. This equation explicitly shows the shape dependence of an otherwise similar equation (see International Tokamak Reactor, Phase Two A, part III, IAEA-STI/PUB/795, Vienna, 1988, Vol. 1, p. 517). 
17. J. Miller et al., ITER Magnet System, ITER Document Series, No. 26, IAEA, Vienna, 1991.

18. J. Miller, Lawrence Livermore National Laboratory, private communication, May 1991.

19. R. L. Miller et al., "Comparison of EURATOM and U.S. Estimates of Fusion Reactor Costs," Fusion Technology 19, 813 (1991).

20. W. D. Spears, ITER Project Cost Estimate, ITER CDA internal report, November 1990. (This report was distributed to the ITER home team leaders.)

21. B. G. Logan et al., MARS-Mirror Advanced Reactor Study, UCRL-53480, Lawrence Livermore National Laboratory, 1984.

22. J. Delene, Oak Ridge National Laboratory, private communication, June 1990.

23. J. Delene, "Updated Comparison of Economics of Fusion Reactors with Advanced Fission Reactors," Fusion Technology 19, 807 (1991).

24. C. G. Bathke, "Effects of Cyclic Fatigue on the Pulsed Advanced Reactor: PULSAR," Memorandum A-3:93-97(u), Los Alamos National Laboratory, April 20, 1993. 


\section{Appendix A \\ DIRECT COST CALCULATION}

The direct cost method described here was developed to model ITER-CDA-like devices and is normalized to the ITER-CDA device. ${ }^{1}$ As such, these costs should be interpreted as first-of-a-kind costs and tend to be higher than those used in tenth-of-a-kind costing methods. ${ }^{2,3}$ All costs are in $1989 \$$ and are assumed to be the manufacturer's costs from the acceptance of "build-to-print" drawings. As such, only manufacturer's R\&D costs (i.e., for prototype or sample construction) are included; R\&D to check that a design solution is feasible, materials R\&D, physics R\&D, etc., are not included. A contingency is included for items not explicitly accounted for, but not to account for uncertainties in unit costs. Also excluded are all engineering design costs (other than those of the manufacturer), transport, taxes, insurance, and tokamak assembly. Some of these costs (engineering and R\&D) that are not accounted for are assumed to be borne by the ITER activity in the EDA. 
Table A-1. Direct cost scalings used in the SUPERCODE

(when not explicitly stated, the scalings listed provide costs in 1989 \$M)

\begin{tabular}{|c|c|}
\hline Category & $\begin{array}{l}\text { Cost scaling } \\
(1989 \$ M)\end{array}$ \\
\hline \multicolumn{2}{|l|}{ Site and facilities } \\
\hline Land & $\$ 16 \mathrm{M}$ \\
\hline Reactor building & $4.0 \times 10^{-4}$ reactor building volume $\left(\mathrm{m}^{-3}\right)$ \\
\hline Maintenance buildings & $\begin{array}{l}2.6 \times 10^{-4} \text { maintenance building volume }\left(\mathrm{m}^{-3}\right)+ \\
4.6 \times 10^{-4} \text { warm cell building volume }\left(\mathrm{m}^{-3}\right)\end{array}$ \\
\hline Tritium building & $3.7 \times 10^{-4}$ tritium building volume $\left(\mathrm{m}^{-3}\right)$ \\
\hline Electrical equipment building & $\begin{array}{l}3.8 \times 10^{-4} \text { electric equipment building volume } \\
\left(\mathrm{m}^{-3}\right)\end{array}$ \\
\hline Cryogenic building & $4.6 \times 10^{-4}$ cryogenic building volume $\left(\mathrm{m}^{-3}\right)$ \\
\hline Other buildings & $\$ 50.5 \mathrm{M}$ \\
\hline \multicolumn{2}{|l|}{ Reactor systems } \\
\hline First wall & $10+0.113$ first wall area, $\mathrm{m}^{2}$ \\
\hline Blanket steel ${ }^{a}$ & $\$ 75 / \mathrm{kg}$ \\
\hline Blanket beryllium ${ }^{a}$ & $\$ 600 / \mathrm{kg}$ \\
\hline Blanket breeding material $a$ & $\$ 1500 / \mathrm{kg}$ \\
\hline Shield material $b$ & $\$ 32 / \mathrm{kg}$ \\
\hline Vacuum vessel & $\$ 32 / \mathrm{kg}$ \\
\hline Gravity support & $\$ 35 / \mathrm{kg}$ \\
\hline Divertor & 0.28 divertor surface area, $\mathrm{m}^{2}$ \\
\hline \multicolumn{2}{|l|}{ Magnets } \\
\hline \multicolumn{2}{|l|}{ TF coils ${ }^{c}$} \\
\hline TF coil conductor & $\begin{array}{l}(650-600 \times \text { copper fraction) } \$ / \mathrm{kg}+\$ 30 / \mathrm{kg} \\
\text { sheath material }+\$ 80 / \mathrm{m} \text { fixed charge }\end{array}$ \\
\hline TF winding pack assembly & $\begin{array}{l}\$ 30 / \mathrm{kg} \text { (of total winding pack) }+\$ 1000 / \text { joint }+ \\
\$ 300 / \mathrm{m} \text { winding charge }\end{array}$ \\
\hline TF coil external case & $\$ 50 / \mathrm{kg}$ \\
\hline Intercoil structure & $\$ 35 / \mathrm{kg}$ \\
\hline TFC gravity support & $\$ 35 / \mathrm{kg}$ \\
\hline \multicolumn{2}{|l|}{ PF coils ${ }^{d}$} \\
\hline Non-OH coils & $5 \times 10^{-6} \sum_{\text {coils }} R_{\text {coil }}(m) B_{\text {max-coil }}(T) I_{\max -\text { coil }}(A)$ \\
\hline $\mathrm{OHC}$ & Same as the IF coils \\
\hline Cryostat assembly & $\$ 32 / \mathrm{kg}$ \\
\hline Injection power & $\$ 3.3 / \mathrm{W}$ delivered to the plasma \\
\hline
\end{tabular}


Table A-1 (continued)

Category

Cost scaling

(1989 \$M)

\begin{tabular}{|c|c|}
\hline \multicolumn{2}{|l|}{ Vacuum systems } \\
\hline High vacuum pumps & $\$ 0.39 \mathrm{M} /$ pump \\
\hline Backing pumps & $\$ 0.3 \mathrm{M} /$ duct \\
\hline Ducts & $\$ 0.04 \mathrm{M} / \mathrm{m}$ duct \\
\hline Valves & $\$ 0.39 \mathrm{M} 2 N_{\text {ducts }}(2.4 \text { duct radius }(\mathrm{m})\}^{1.4}$ \\
\hline Duct shielding & $\$ 26 / \mathrm{kg}$ duct shielding \\
\hline Other & $\$ 1.3 \mathrm{M}$ \\
\hline \multicolumn{2}{|l|}{ Power conditioning } \\
\hline \multicolumn{2}{|l|}{ TF coils } \\
\hline $\begin{array}{l}\text { Power supplies }(\$ M) \\
\text { Breakers }(\$ M)\end{array}$ & $\begin{array}{l}1.22 \times 10^{-6} N_{\mathrm{TF}}\left[I_{\mathrm{TF}}(A) V_{\mathrm{dump}}(V)\right]^{0.7} \\
+1 \times 10^{-6} I_{\mathrm{TF}}(A)\end{array}$ \\
\hline Resistors (\$M) & $0.175 W_{\text {stored }}(g J)+2.5 \times 10^{-3} N_{\mathrm{TF}}$ \\
\hline$I \& C(\$ M)$ & $0.3 N_{\mathrm{TF}}$ \\
\hline Bussing & $1.23 \times 10^{-7} I_{\mathrm{TF}}(A) \times$ bus length $(\mathrm{m})$ \\
\hline \multicolumn{2}{|l|}{ PF coils } \\
\hline Power supplies (\$M) & $0.035 \times$ peak MVA \\
\hline I\&C & $\$ 0.3 \mathrm{M} \times N_{\mathrm{PF}}$ \\
\hline Bussing (\$M) & $2.1 \times 10^{-7}\left\langle I_{\max -\mathrm{PF}}\right\rangle(A)$ PF bus length (m) \\
\hline Burn power supplies & $4.9 \times 10^{-3} N_{\mathrm{PF}}\left(\left\langle P_{\text {resistive }} / \text { coil }\right\rangle(W)\right)^{0.7}$ \\
\hline Breakers & $0.0166 N_{\mathrm{PF}}\left(\left\langle I_{\max -\mathrm{pf}}\right\rangle\left\langle V_{\max -\mathrm{PF}}\right\rangle[V A]\right)^{0.7}$ \\
\hline Resistors & $0.0015 \max$ PF stored energy, $\mathrm{MJ}$ \\
\hline AC breakers & $0.075 N_{\mathrm{PF}}$ \\
\hline \multicolumn{2}{|l|}{ Main heat transport } \\
\hline Primary coolant $f$ & $0.162 P_{\text {thermal }}^{0.8}, \mathrm{MW}$ \\
\hline Intermediate coolant ${ }^{f}$ & $0.162 P_{\text {thermal }} 0.8, \mathrm{MW}$ \\
\hline Cryogenic system 8 & $0.093\left(4.5 / T_{\text {cryo }}[K]\right) \times P_{\text {cryo }} 0.67, \mathrm{~W}$ \\
\hline \multicolumn{2}{|l|}{ Fuel handling } \\
\hline Fueling system $h$ & $\$ 22.3 \mathrm{M}$ \\
\hline Processing/purification & $44\left\{0.5+0.5\right.$ (gas load[grams/day]/60) $\left.^{0.67}\right\}$ \\
\hline Atmospheric recovery $i$ & $2.1 \times 10^{-4} V_{\text {nuclear }}\left[\mathrm{m}^{-3}\right]$ \\
\hline Nuclear building ventilation & $1 \times 10^{-3}\left(V_{\text {nuclear }}\left[\mathrm{m}^{-3}\right]\right)^{0.8}$ \\
\hline
\end{tabular}


Table A-1 (continued)

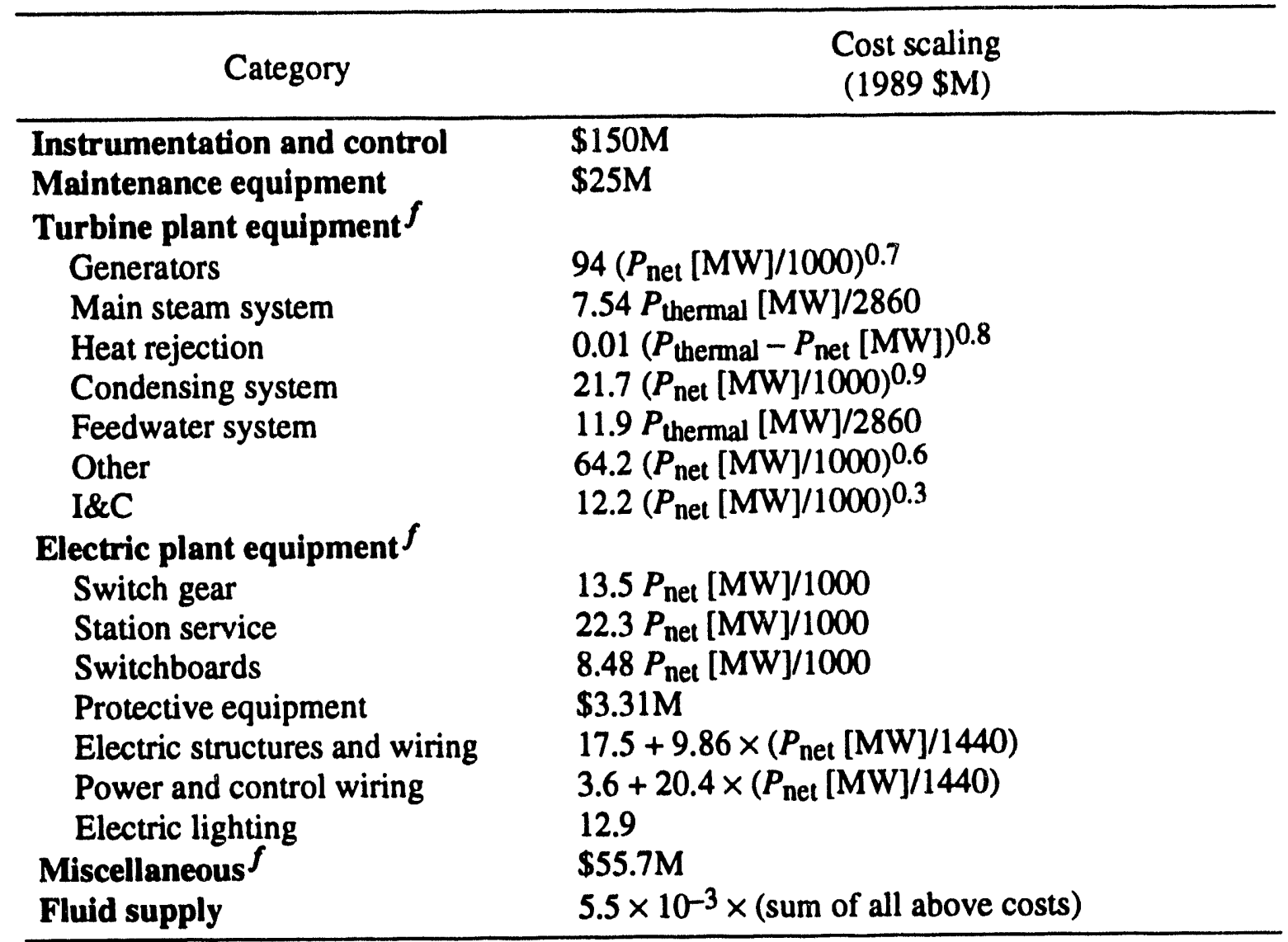

aThe blanket is a complex design and therefore has higher unit costs than, for example, the shield. Following an ITER-CDA design, we assumed a $25 \%$ blanket coolant volume fraction, an $8 \%$ breeder fraction, a $60 \%$ beryllium fraction, and a $9 \%$ structure fraction.

$b$ For a plate-type stainless steel shield material; this also applies to the penetration shielding surrounding the device.

These scalings are applicable to a $\mathrm{Nb}_{3} \mathrm{Sn}$ cable-in-conduit design.

$d$ We cost the Ohmic Heating Central Solenoid (OHC) in more detail than the other PF coils because its parameters can be determined with more certainty. The other equilibrium PF coils are costed with a simple "Amp-m-T" scaling.

$e_{N P F C}=$ number of PFC circuits; taken to be one circuit per symmetric coil set.

fTaken from Ref. 3 (ARIES-1) and updated to 1989 \$.

$\boldsymbol{g} T_{\text {cryo }}$ is the temperature of the cryogenic system (5K here), and $\boldsymbol{P}_{\text {cryo }}$ is the peak heat-removal requirement.

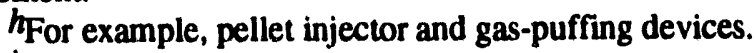

$i V_{\text {nuclear }}$ is the internal volume of the nuclear buildings (i.e., the reactor hall and the warm cell building). 


\section{REFERENCES}

1. W. D. Spears, ITER Project Cost Estimate, ITER CDA internal report, November 1990. (This report was distributed to the ITER home team leaders.)

2. J. Sheffield et al., "Cost Assessment of a Generic Magnetic Fusion Reactor," Fusion Technology 9, 199 (1986).

3. F. Najmabadi et al., The ARIES-I Tokamak Reactor Study, UCLA-PPG-1323, 1991. 
ORNL/TM-12483

Dist. Category UC-420

\section{INTERNAL DISTRIBUTION}

1. C. C. Baker

2. L. A. Berry

3. B. A. Carreras

4. R. A. Dory

5-6. J. D. Galambos

7. D. J. Hoffman

8. R. P. Leinius

9. M. S. Lubell

10. J. F. Lyon

11. S. L. Milora

12. Y-K. M. Peng
13. T. E. Shannon

14. J. Sheffield

15. C. C. Southmayd

16. N. A. Uckan

17. Central Research Library

18. Document Reference Section

19. Fusion Energy Division Library

20-21. ET/FE Publications Office

22. ORNL Patent Section

23-24. Laboratory Records Department

25. Laboratory Records, RC

\section{EXTERNAL DISTRIBUTION}

26. Office of the Assistant Manager for Energy Research and Development, U.S. Department of Energy, ORO, P.O. Box 2000, Oak Ridge, TN 37831

27. N. A. Davies, Director, Office of Fusion Energy, Office of Energy Research, ER-50 Germantown, U.S. Department of Energy, Washington, DC 20545

28. M. Roberts, International Programs, Office of Fusion Energy, Office of Energy

Research, ER-52 Germantown, U.S. Department of Energy, Washington, DC 20545

29. D. E. Baldwin, Lawrence Livermore National Laboratory, P.O. Box 5511, Livermore, CA 94550

30. S. Haney, Lawrence Livermore National Laboratory, P.O. Box 5511, Livermore, CA 94550

31. L. J. Perkins, Lawrence Livermore National Laboratory, P.O. Box 5511, Livermore, CA 94550

32. R. W. Conn, Engineering IV, 405 Hilgard Avenue, University of California, Los Angeles, CA 90024-1597

33. P. C. Liewer, MS 138-208, Jet Propulsion Laboratory, 4800 Oak Grove Drive, Pasadena, CA 91109

34. R. Parker, Plasma Fusion Center, Massachusetts Institute of Technology, 167 Albany St., NW16-288, Cambridge, MA 02139

35. K. I. Thomassen, L-637, Lawrence Livermore National Laboratory, P.O. Box 5511, Livermore, CA 94550

36. R. Aymar, CEN/Cadarache, Departement de Recherches sur la Fusion Contrôlée, F-13108 Saint-Paul-lez-Durance Cedex, France

37. C. Bathke, Los Alamos National Laboratory, P.O. Box 1663 (MS-F607), Los Alamos, NM 87545

38. J. D. Callen, Department of Nuclear Engineering, University of Wisconsin, Madison, WI 53706-1687 
39. S. O. Dean, Fusion Power Associates, Inc., 2 Professional Drive, Suite 248, Gaithersburg, MD 20879

40. D. Ehst, Argonne National Laboratory, 9700 South Cass Avenue, Bldg. 205 , Argonne, IL 60439

41. H. K. Forsen, Bechtel Group, Inc., Research Engineering, P.O. Box 3965, San Francisco, CA 94119

42. K. Fowler, University of California at Berkeley, Berkeley, CA 92740

43. R. J. Goldston, Princeton Plasma Physics Laboratory, Princeton University, P.O. Box 451, Princeton, NJ 08543

44. R. W. Gould, Department of Applied Physics, California Institute of Technology, Pasadena, CA 91125

45. R. A. Gross, Plasma Research Laboratory, Columbia University, New York, NY 10027

46. R. J. Hawryluk, Princeton Plasma Physics Laboratory, P.O. Box 451, Princeton, NJ 08543

47. B. Krakowski, Los Alamos National Laboratory, P.O. Box 1663 (MS-F607), Los Alamos, NM 87545

48. T. K. Mau, University of California, Los Angeles, Los Angeles, CA 90024-1597

49. D. M. Meade, Princeton Plasma Physics Laboratory, P.O. Box 451, Princeton, NJ 08543

50. R. Miller, Los Alamos National Laboratory, P.O. Box 1663 (MS-F607), Los Alamos, NM 87545

51. H. Neilson, Princeton Plasma Physics Laboratory, Princeton University, P.O. Box 451, Princeton, NJ 08543

52. N. Nevins, Lawrence Livermore National Laboratory, P.O. Box 808 (L636), Livermore, CA 94550

53. S. Piet, ITER, Joint Central Team, 11025 N. Torrey Pines Rd., La Jolla, CA 92037

54. D. Post, ITER, Joint Central Team, San Diego Co Center, 11025 North Torrey Pines Rd., La Jolla, CA 92037

55. P. H. Rutherford, Princeton Plasma Physics Laboratory, Princeton University, P.O. Box 451, Princeton, NJ 08543

56. J. Mandrekas, Fusion Research Center and Nuclear Engineering Program ESM Building 0225, Georgia Institute of Technology, Atlanta, GA 30332

57. W. M. Stacey, Fusion Research Center and Nuclear Engineering Program ESM Building 0225, Georgia Institute of Technology, Atlanta, GA 30332

58. D. Steiner, Nuclear Engineering Department, NES Building, Tibbetts Avenue, Rensselaer Polytechnic Institute, Troy, NY 12181

59. R. Varma, Physical Research Laboratory, Navrangpura, Ahmedabad 380009, India

6C. J. Wesley, ITER, San Diego Co Center, 11025 North Torrey Pines Rd., La Jolla, CA 92037

61. Bibliothek, Max-Planck Institut für Plasmaphysik, Boltzmannstrasse 2, D-8046 Garching, Federal Republic of Germany

62. Bibliothek, Institut für Plasmaphysik, KFA Jülich GmbH, Postfach 1913, D-5170 Jülich, Federal Republic of Germany 
63. Bibliothek, KfK Karlsruhe GmbH, Postfach 3640, D-7500 Karlsruhe 1, Federal Republic of Germany

64. Bibliotheque, Centre de Recherches en Physique des Plasmas, Ecole Polytechnique Fédérale de Lausanne, 21 Avenue des Bains, $\mathrm{CH}-1007$ Lausanne, Switzerland

65. Bibliothèque, CEN/Cadarache, F-13108 Saint-Paul-lez-Durance Cedex, France

66. Library, JET Joint Undertaking, Abingdon, Oxfordshire OX14 3EA, England

67. Library, FOM-Instituut voor Plasmafysica, Rijnhuizen, Edisonbaan 14, 3439 MN Nieuwegein, The Netherlands

68. Library, National Institute for Fusion Science, Chikusa-ku, Nagoya 464-01, Japan

69. Library, International Centre for Theoretical Physics, P.O. Box 586, I-34100 Trieste, Italy

70. Library, Centro Richerche Energia Frascati, C.P. 65, I-00044 Frascati (Roma), Italy

71. Library, Plasma Physics Laboratory, Kyoto University, Gokasho, Uji, Kyoto 611, Japan

72. Library, Japan Atomic Energy Research Institute, Naka Fusion Research Establishment, 801-1 Mukoyama, Naka-machi, Naka-gun, Ibaraki-ken, Japan

73. Plasma Research Laboratory, Australian National University, P.O. Box 4, Canberra, A.C.T. 2601, Australia

74-111. Given distribution as shown in DOE/OSTI-45(10-R75 under category UC-420, Magnetic Fusion Energy 

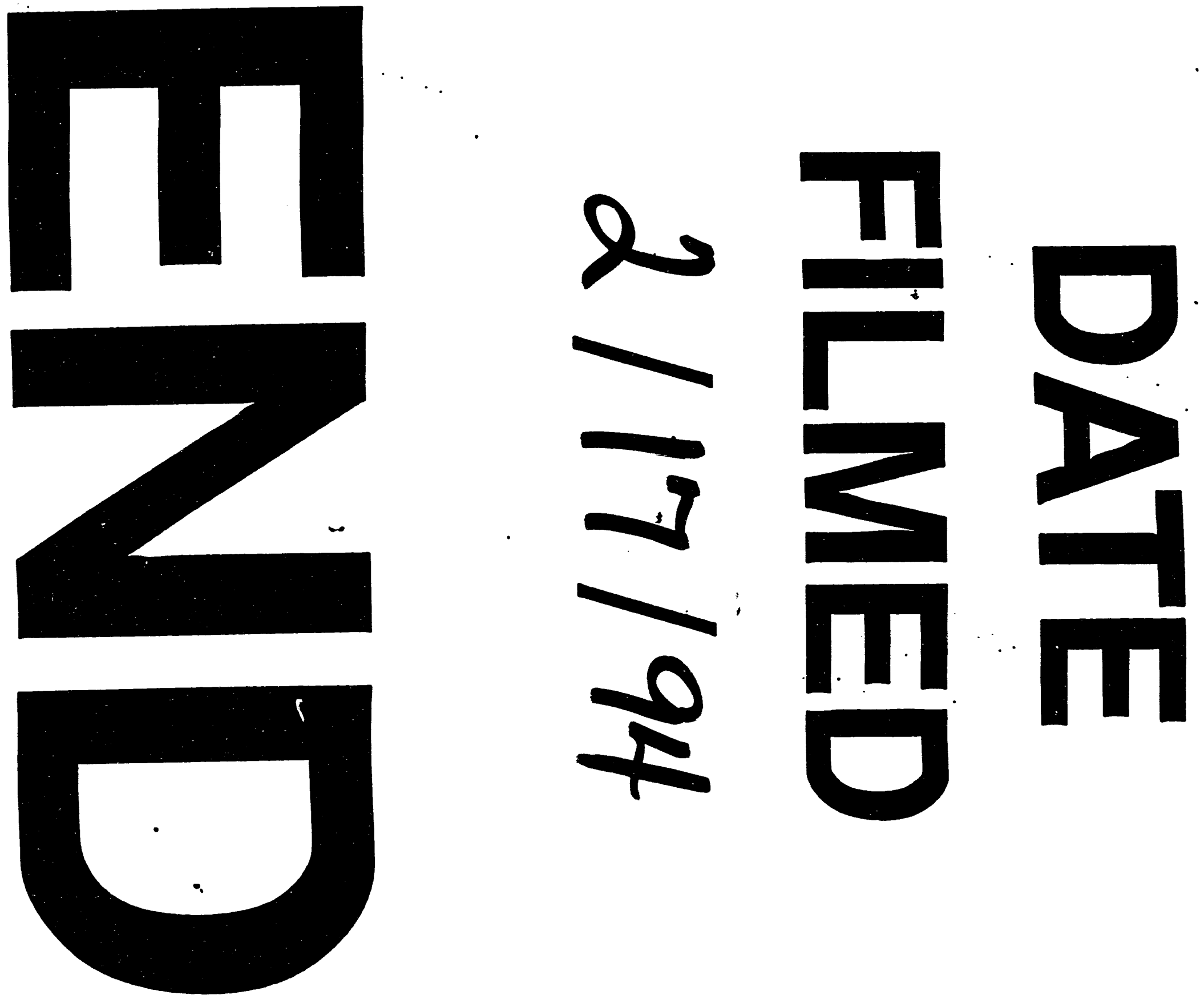


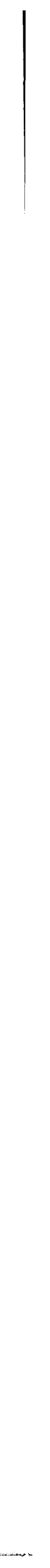

